Maslon et al.

\title{
Slow transcriptional elongation causes embryonic lethality and perturbs kinetic coupling of long neural genes
}

Magdalena M. Maslon', Ulrich Braunschweig', Stuart Aitken', Abigail R. Mann', Fiona Kilanowski ${ }^{1}$, Chris J. Hunter ${ }^{1}$, Benjamin J. Blencowe ${ }^{2}$, Alberto R. Kornblihtt ${ }^{3}$, Ian R. Adams ${ }^{1}$ and Javier F. Cáceres ${ }^{1}$

${ }^{1}$ MRC Human Genetics Unit, Institute of Genetics and Molecular Medicine, University of Edinburgh, UK; ${ }^{2}$ Donnelly Centre, University of Toronto, Ontario M5S 3E1, Canada; ${ }^{3}$ Instituto de Fisiología, Biología Molecular y Neurociencias (IFIBYNE-UBACONICET) and Departamento de Fisiología, Biología Molecular y Celular, Facultad de Ciencias Exactas y Naturales, Universidad de Buenos Aires, Ciudad Universitaria, C1428EHA Buenos Aires, Argentina.

Correspondence should be addressed to:

Ian.Adams@igmm.ed.ac.uk, Javier.Caceres@igmm.ed.ac.uk

Running title: Transcriptional elongation rate controls gene expression and AS during development 
Maslon et al.

The rate of RNA Polymerase II (RNAPII) elongation has an important role in the control of Alternative splicing (AS); however, the in vivo consequences of an altered elongation rate are unknown. Here, we generated mouse embryonic stem cells (ESCs) knocked-in for a slow elongating form of RNAPII. We show that a reduced transcriptional elongation rate results in early embryonic lethality in mice and impairs the differentiation of ESCs into the neural lineage. This is accompanied by changes in splicing and in gene expression in ESCs and along the pathway of neuronal differentiation. In particular, we found a crucial role for RNAPII elongation rate in transcription and splicing of long neuronal genes involved in synapse signaling. The impact of the kinetic coupling of RNAPII elongation rate with AS is more predominant in ESC-differentiated neurons than in pluripotent cells. Our results demonstrate the requirement for an appropriate transcriptional elongation rate to ensure proper gene expression and to regulate AS during development.

[Keywords: RNA polymerase II; transcription elongation; kinetic coupling; mouse model, ESCs differentiation, neurons]

Supplemental material is available for this article. 
Alternative splicing (AS) is a highly regulated process that generates RNA diversity and is a major contributor to protein isoform diversity. Its regulation not only depends on the interaction of trans-acting factors with regulatory RNA cis-acting sequences but also on multiple layers of regulation, which include DNA methylation, chromatin structure and modification, and transcription ${ }^{1,2}$. The co-transcriptional nature of premRNA splicing led to the suggestion that the rate of transcription elongation acts to control AS in mammalian cells $\mathrm{s}^{3,4}$. Notably, there is a functional relationship between the transcriptional and the splicing machineries, as evidenced by the role of splicing factors, such as TCERG1/CA150 5 and $\mathrm{SRSF} 2^{6}$, in stimulating transcriptional elongation. A role for transcription elongation rate influencing splicing fidelity and cotranscriptionality was also observed in yeast ${ }^{7,8}$.

Recent studies revisited the contribution of the kinetics of RNAPII elongation to the regulation of AS, giving rise to two complementary models", ${ }^{2,9}$ The "window of opportunity" or kinetic model of AS regulation proposes that the rate of RNAPII elongation influences the outcome of alternative splicing selection. Use of a mutant form of RNAPII (C4/R749H) with a slower elongation rate leads to an increased ${ }^{10}$ or decreased $^{11}$ inclusion of alternative cassette exons into mature mRNA. A complementary model, termed 'Goldilocks', concluded based on the study of RNAPII mutants with both slow and fast elongation rates, that an optimal rate of transcriptional elongation is required for normal co-transcriptional pre-mRNA splicing ${ }^{12}$. In both models, recruitment of splicing regulators to cis-acting RNA sequences as well as nascent RNA folding are influenced by the elongation rate of RNAPII ${ }^{13-15}$. The global impact of RNAPII elongation rate in the regulation of AS was confirmed with the use of drugs that inhibit RNAPII elongation ${ }^{16}$. 
Maslon et al.

Exogenous agents also affect transcriptional coupling to AS. For instance, UV irradiation promotes RNAPII hyperphosphorylation with the subsequent inhibition of transcriptional elongation, leading to changes in AS, suggesting that transcriptional coupling to AS is a key feature of the DNA-damage response ${ }^{17,18}$. So far, all studies in mammalian systems investigating the link between transcription elongation and AS have been confined to the use of cultured cells transfected with an $\alpha$-amanitin-resistant slow or fast elongating RNAPII. The consequences of this mechanism of regulation in vivo remain unexplored.

Here, we sought to address how does an altered transcriptional elongation rate affect gene expression and the control of AS and impacts on mammalian development. We generated mouse embryonic stem cells (ESCs) knocked-in for a slow RNAPII mutant (C4/R749H). We show that an appropriate RNAPII elongation rate is essential for proper mouse development. We observed that a reduced elongation rate results in major changes in splicing and in gene expression in pluripotent ESCs and along the pathway of neuronal differentiation. The impact of the kinetic coupling of RNAPII elongation rate with AS is more predominant in ESC-differentiated neurons than in pluripotent cells, as it is essential for the expression and splicing of neuron-specific genes involved in synapse signaling. 
Maslon et al.

\section{Results}

\section{Generation of a slow RNAPII knock-in mutant mouse ES cells}

To address the consequences of an altered transcriptional elongation rate for gene expression and for the kinetic control of AS, we set out to generate an in vivo model of a slow RNAPII by introducing a heterozygous or homozygous R749H mutation into the endogenous Polr2a in mouse ESCs. This mutation is equivalent to the $\mathrm{C} 4$ point mutation identified in the Drosophila pol II largest subunit, which confers a lower elongation rate, is less capable of transcribing through natural elongation blocks, and causes non-lethal developmental defects in the heterozygous state ${ }^{19-21}$. Gene targeting in mouse ESCs was achieved by rounds of homologous recombination to introduce the R749H mutation into each allele of Polr $2 a$ to generate heterozygous and homozygous ESCs (Fig. 1a, henceforth referred to as WT/slow and slow/slow ESCs). We verified the correct targeting by PCR of genomic DNA isolated from these ESCs and a diagnostic XhoI digest (Fig. 1b). Ion Torrent sequencing of overlapping PCR products from ESC genomic DNA encompassing a $\sim 14 \mathrm{~kb}$ region around the $\mathrm{R} 749 \mathrm{H}$ mutation confirmed that the heterozygous WT/slow and homozygous slow/slow ESCs contained no genomic re-arrangements or additional mutations in this region relative to the parental WT/WT ESCs. We verified the expression of mutant RNAPII in these cells by cDNA sequencing (Fig. 1c) and using allele-specific RT-qPCR (Fig. 1d).

\section{Slow transcription elongation hinders early mouse development}

The WT/slow ESCs were used to generate a slow RNAPII knock-in mouse model by injection into C57BL/6 blastocysts. We obtained mouse chimaeras from these injections; however, no germline transmission was observed upon breeding 8 male animals with at least $30 \%$ coat colour chimaerism to C57BL/6 females. These chimaeric 
Maslon et al.

animals either sired only host blastocyst-derived offspring or were infertile and lacked sperm in the epididymis. As a test, breeding of 3-4 male chimaeras is typically sufficient to detect germline transmission ${ }^{22}$. ESCs with a heterozygous slow RNAPII appear to be unable to functionally contribute to spermatogenesis. To investigate the developmental consequences of the Polr $2 a$ R749H mutation further, we set out to generate R749H mutant mice using CRISPR/Cas9 (Fig. 2a). Specific single guide RNAs (sgRNAs) against Polr2a were microinjected into (C57BL/6 x CBA) F2 zygotes along with the Cas9 mRNA and an oligonucleotide repair template containing the R749H mutation ("slow oligo") and subsequently embryos were transferred into pseudopregnant recipient mice at the two-cell stage. No live-borne mice were obtained containing homozygous or even heterozygous mutations in the Polr2a locus among the 47 pups (Fig. 2b). To rule out inefficient induction of double-strand DNA breaks (DSBs) by sgRNAs, or inefficient oligonucleotide-mediated repair at this locus, we coinjected the same pair of sgRNAs with a repair template mixture containing a 1:1 ratio of a slow oligo and a silent oligo, the latter being a repair template containing silent mutations. Again, we could not detect the slow mutation in any of the 51 pups born; however, we obtained two homozygotes and four heterozygotes as a result of repair with silent oligo (Fig. 2c). Taken together, the ESC chimaeras and the CRISPR/Cas9 microinjections suggest that even heterozygosity for Polr2a R749H causes developmental defects in mice. Next, we investigated at what stage the Polr $2 a \mathrm{R} 749 \mathrm{H}$ mutation caused embryonic lethality. We microinjected slow oligo along with guide RNAs into zygotes, cultured the zygotes in vitro for 3 days, and analyzed the resulting embryos at the late morula/blastocyst stage. We found several slow heterozygous embryos and only 1 homozygous embryo, revealing that the $\mathrm{R} 749 \mathrm{H}$ mutation was tolerated at the pre-implantation stage (Fig. 2b and c). However, when microinjected 
Maslon et al.

zygotes were transferred to pseudopregnant recipient females at the 2-cell stage to allow them to implant and develop further, only one heterozygous and no homozygous slow mutations were found in mid-gestation embryos at E9.5-E11.5 (Fig. 2c). Thus, we conclude that the Polr $2 A$ R749H mutation causes early embryonic lethality.

\section{The $\mathbf{R 7 4 9 H}$ mutation decreases the transcription elongation rate in mouse ESCs}

We analyzed the effect of the slow RNAPII mutation in ESCs using 5,6dichlorobenzimidazole 1-beta-D-ribofuranoside (DRB) to measure RNAPII transcriptional elongation rates ${ }^{23}$. DRB inhibits $\mathrm{P}-\mathrm{TEFb}$-dependent phosphorylation of the transcription elongation factor Spt5 and of Serine 2 in the carboxy-terminal domain (CTD) of RNAPII. Thus, newly initiated RNAPII cannot progress to the elongation phase; however, upon DRB removal, all initiated polymerases are released, and the appearance of selected intron-exon junctions can be monitored by qRT-PCR in a timedependent manner. We monitored how transcription proceeded through the Itprl and Utrophin genes, following DRB removal. Transcription over the first exon-intron junctions did not differ between the wild-type (WT) and mutant cell lines (Supplementary Fig. 1, Exon 1-Intron 1 panels). However, appreciable pre-mRNA levels at the more downstream exon-intron junctions were detected earlier in WT than in slow/slow cells. For example, the appearance of an exon-intron junction $133 \mathrm{~kb}$ downstream from the Itprl transcription start site was detected at 40 min post-DRB release for the WT, as compared to 90 min for the mutant RNAPII (Supplementary Fig. 1a, see Exon 5-Intron 5 panel). An overall mean elongation rate across Itprl and Utrophin was estimated to be $3.3 \mathrm{~kb} / \mathrm{min}$ and $5.6 \mathrm{~kb} / \mathrm{min}$, respectively in WT cells, as compared to $1.5 \mathrm{~kb} / \mathrm{min}$ and $1 \mathrm{~kb} / \mathrm{min}$ in slow/slow cells. We also measured overall transcription using a reversible DRB block followed by incubation with medium 
containing tritiated $(3 \mathrm{H})$-Uridine. Time-resolved accumulation of newly made RNA, as measured by the incorporation of $3 \mathrm{H}$-Uridine, was attenuated in slow/slow in comparison to WT ESCs (Supplementary Fig. 1b). We also found that nuclear extracts isolated from slow/slow cells were less efficient in driving the production of a run-off transcript from the artificial DNA template (Supplementary Fig. 1c). These results are in agreement with the previous observation that the R749H mutation in RNAPII leads to approximately a two-fold decrease in the transcription elongation rate in vitro ${ }^{24}$ and that the elongation rate positively correlates with expression levels ${ }^{25,26}$.

Next, we analyzed RNAPII elongation rates genome-wide using metabolic labeling of newly transcribed RNAs by the uridine analogue, 4-thiouridine $(4 \mathrm{sU})^{27,28}$. Transcription was arrested with DRB for 3 hours, then DRB was removed and cells were allowed to transcribe for 5 and 15 mins. To label the newly transcribed RNA, cells were pulsed with $4 \mathrm{sU}$ for the last 10 min of each time point (Fig. 3a). Cells not released from transcriptional block ("0 min") were also labeled with 4sU. Following biotinylation and purification, 4sU-labeled RNAs were subjected to deep sequencing. At time "0 min", which corresponds to the release from DRB inhibition, the vast majority of reads were observed over a narrow area near the promoter (Fig. 3b, black line, Supplementary Fig. 2a, top panel). As time progresses, the reads from nascent RNA are observed further into the gene bodies, referred to as the transcription "wave front" progression (Supplementary Fig. 2a, wave front progression in Notch1). On average, we observed that in WT cells, RNAPII had progressed approximately $11 \mathrm{~kb}$ into the gene at $5 \mathrm{~min}$ and up to $35.8 \mathrm{~kb}$ after $15 \mathrm{~min}$ after DRB removal. By contrast, in slow/slow cells the transcription wave-fronts reached only $8.6 \mathrm{~kb}$ and $26.7 \mathrm{~kb}$ at 5 and 15 min time points, respectively (Supplementary Fig. 2b and Fig. 3b). Genomewide, we observed an average elongation rate of 2,450 bases/min in wild-type cells, but 
reduced rates of 1,780 bases/min in slow/slow cells (Fig. 3b, d). Previous work suggests that the speed of RNAPII differs between genes ${ }^{25,26}$. The density plot of reported elongation rates demonstrates that the dynamic range of transcription rates is narrower in slow RNAPII cells, whilst in wild-type cells it seems to be bimodal revealing a population of RNAPII transcribing at higher rates (Fig. 3c). Indeed, most genes have a lower elongation rate in slow/slow cells in comparison to wild-type cells (e.g. Ern1 is transcribed at $4.2 \mathrm{~kb} / \mathrm{min}$ and $1.9 \mathrm{~kb} / \mathrm{min}$, in wild type and slow $/$ slow cells, respectively, Supplementary table 1). Interestingly, there are examples of genes that are transcribed faster in slow/slow cells. A slower elongation rate might lead to a longer residence time, allowing more time for positive factors to bind and/or stimulate RNAPII and consequently lead to overall higher transcription rates for these genes. Finally, there is a positive correlation between elongation rate and expression levels (Supplementary Fig. 2c), indicating that on average, highly expressed genes have faster elongation rates in agreement with previous reports ${ }^{25,26}$. Overall, these data validate previous results obtained in cultured cells transfected with an $\alpha$-amanitin-resistant RNAPII harboring the C4 mutation ${ }^{10,12}$ and confirms that the endogenous knock-in of a slow RNAPII mutation affects negatively the transcriptional elongation rate in mouse ESCs.

\section{Role of transcriptional elongation during neural differentiation}

To assess whether a differential transcription elongation rate affects ESC differentiation, we exploited an in vitro model of neuronal development. During embryonic development, different pathways control self-renewal and differentiation capacity of neural progenitors ${ }^{29,30}$. We used a serum-free adherent monolayer culture protocol $^{31,32}$, that generates multipotent Sox 1 and Nestin-positive neuronal progenitor cells (NPCs) (Fig. 4a). The ESC-derived NPCs can then be used to generate neural stem 
cells (NSCs) by allowing these cells to form floating aggregates in epidermal/fibroblast growth factor 2 (EGF/FGF2)-containing medium that then outgrow a population of bipolar NSCs when plated in adherent conditions (Fig. 4a). The initial heterogeneity of NSC-containing cell population is reduced following a few passages. Alternatively, the ESC-derived NPCs can be differentiated into all three neural lineages. For example, when cultured adherently on poly-ornithine/laminin in media containing cAMP and ascorbic acid, NPCs differentiate into Tuj1+ immature neuronal cells and further into Map2-positive mature post-mitotic neurons.

We first attempted to differentiate WT ESCs and slow/slow ESCs into NPCs; however, we observed decreased proliferation or compromised differentiation potential of slow/slow cells. Nevertheless, we found that both wild-type and slow/slow cells generated Sox1, Pax6 and Nestin-positive NPCs (Fig. 4b). We next tested if we could generate NSCs from slow/slow ESC-derived NPCs. Interestingly, we found that despite obtaining neural aggregates (Fig. 4c), slow/slow NSCs could not be maintained in EGF/FGF2 proliferating conditions (Fig. 4d and data not shown). Instead, following a few passages we noted the appearance of flattened differentiated cells in the slow/slow cultures, and subsequently we observed overwhelming cellular death. Strikingly, amongst some of the remaining Nestin-positive cells in these slow/slow cultures, we observed promiscuous differentiation to Tuj1+ cells (Fig. 4d and data not shown). These results suggest that the balance between maintenance of the self-renewing cell state and differentiation might be perturbed in slow/slow NSCs.

Indeed, when we performed Gene Ontology (GO) analysis of genes upregulated in NPCs and in aggregates (AGG) (Supplementary Table 2), we found they were involved in neuronal functions (Supplementary Fig. 3a), which might explain some of the phenotypes observed in slow/slow NSCs (Fig. 4). We observed upregulation of Ascll, 
Maslon et al.

Nr2f1, Crabp2 and Nr6a1 genes (Supplementary Fig. 3b) in slow/slow NPCs and AGG. Their overexpression has been previously shown to suppress proliferation of progenitor cells, induce neurogenesis and neuronal maturation ${ }^{33,34}$, and could explain the premature differentiation observed in slow/slow NSCs. In parallel, we observed that the EGF receptor (EGFR) was two-fold downregulated in slow/slow NPCs (Supplementary Table 2). As EGF withdrawal causes massive cell death and premature differentiation observed in slow/slow $\mathrm{NSCs}^{32}$, decreased expression of EGFR in slow/slow NPCs could contribute to the observed lack of their self-renewal in EGF/FGF2 proliferating conditions. Although the slow RNAPII allele appears to impair the maintenance of NSCs, the presence of differentiated Tuj1 neurons in the NSC cultures (Fig. 4d) suggests that a slow transcriptional elongation rate does not impair neuronal differentiation per se. Indeed, WT and slow/slow ESCs differentiated into immature Tuj1-positive and mature Map2-positive neurons (Fig. 4e, Supplementary Fig. 4a, b). Whereas we observed a robust expression of the synaptic marker (Syn1) in WT neurons, it seemed reduced in slow/slow neurons (Supplementary Fig. 4a, b). Overall these data show that the slow mutation in RNAPII causes problems in the maintenance/self-renewal of NSCs; however, it appears not to interfere with neuronal differentiation per se. It also suggests that neurons harboring a homozygous slow mutant RNAPII might be functionally or developmentally different than WT neurons.

\section{Transcriptional elongation rate influences alternative splicing decisions in ESCs and during neural differentiation}

Next, we investigated gene expression and AS changes by RNA sequencing (RNA-seq) analysis of poly(A)+ RNA isolated from pluripotent ESCs, NPCs and neurons. First, we compared alternative exons usage between wild-type and slow/slow cells using vast 
tools, which assigned a "percentage spliced in" (PSI) value to each exon. Analysis of AS changes revealed 80, 171 and 424 events of enhanced exon inclusion, comprising cassette exons and microexons, in slow/slow ESCs, NPCs and neurons, respectively, as compared to their WT counterparts (Fig. 5a, Supplementary Table 3). We also observed that whereas cassette exon events did not show a bias towards increased exon inclusion in slow/slow ESCs or NPC cells when compared to WT cells, there was some tendency for an increased exon inclusion in neurons $(60 \%$ of alternative cassette exons are more included in slow/slow neurons) (Fig. 5a). By contrast, we found that exon skipping was enhanced relative to cassette inclusion by the slow RNAPII mutant, with 94 and 524 skipped cassette exons and microexons, detected in ESCs and NPCs, respectively. This is compatible with the current models of kinetic coupling, where a slow RNAPII can lead to enhanced exon inclusion if the AS event depends on the recruitment of positive regulators, or to exon skipping, if splicing inhibitors are recruited ${ }^{11}$.

Importantly, the extent of splicing changes was much more pronounced in NPCs and fully differentiated neurons in comparison to ESCs (174 cassette exons and microexon events changing in slow/slow ESCs, as compared to 695 or 704 cassette exons and microexons changes observed in slow/slow NPCs and neurons, respectively, Fig. 5a). Importantly, the extent of AS events observed in the different stages of neuronal differentiation is comparable (Fig. 5a), thus, these results underscore the predominant role of kinetic coupling as differentiation progresses. A possible explanation for this observation is related to changes in chromatin structure during cell differentiation. Chromatin is reported to be more open and accessible in pluripotent ESCs $^{35}$. This differential chromatin organization will likely have a direct influence in the elongation rate of RNAPII ${ }^{2,36}$. Thus, a slow elongating RNAPII will exacerbate the dependence of AS on kinetic coupling upon cellular differentiation, as it is further hindered by the 
compactness of chromatin. Not only, did we observe an elevated number of affected exons in slow/slow neurons in comparison to slow/slow ESC, but also the number of splicing changes increases during differentiation to neurons, with 1,365 alternative splicing events detected in WT cells upon differentiation, whereas this number increases to 2,252 exons in slow/slow cells (Supplementary Table 3). We examined the properties of elongation-rate sensitive exons, namely 5' and 3' splice sites strength, as well as the length of flanking introns and alternative exon ${ }^{37,38}$ (Supplementary Fig. 5a). We noted that exons that were more included in slow/slow ESCs had longer flanking introns (median of 2,335 and 1,546 bases in included and not-affected exons, respectively). Consistent with the 'window-of-opportunity' model of kinetic coupling, these longer introns could contribute to a time delay significant enough to promote recognition and splicing of suboptimal exons in nascent transcripts. By contrast, exons affected in slow/slow neurons did not show such characteristics and seemed to be more dependent on the repertoire of expressed RBPs. For example, RNA maps produced for RNA-binding proteins (CISBP-RNA IUPAC binding motifs ${ }^{39}$ ) revealed that introns downstream of exons skipped in slow/slow neurons are enriched for Nova and Fox1 binding site (Supplementary Fig. 5b) and indeed binding of these factors downstream of alternative exons, has been previously shown to increase their skipping ${ }^{40,41}$.

High-throughput RNA-seq of poly(A)+RNA revealed changes in the expression of several hundreds of genes in slow/slow cells, as compared to their WT counterparts (Supplementary Fig. 6a, b, Supplementary Table 2). We, therefore, looked at whether the observed changes in AS are coupled to changes in the expression of corresponding genes. Notably, the differential splicing observed in the presence of a slow elongating RNAPII is generally not driven by differential gene expression. The exception is some 
Maslon et al.

cases of intron retention, where negative correlation with the expression might reflect frequent coupling of intron retention to NMD (data not shown).

\section{Slow transcription elongation perturbs expression of long synaptic genes}

Enrichment Map visualization of gene-sets enriched amongst downregulated and AS genes in slow/slow neurons revealed that they are involved in programs that are essential for synapse formation and synaptic signaling (Fig. 6a, Supplementary Fig. 7). Indeed, genes downregulated in slow/slow neurons encode proteins involved in the entire life cycle of synaptic vesicles. Amongst them are: Syn1 and Syn2, which tether the vesicle to the actin cytoskeleton ${ }^{42}$, Snap25, Stx1b, Stxbp1, Syt1 proteins, that are involved in synaptic vesicle fusion and recycling; as well as neurexins (including Nrxn1 and Nrxn2) and contactin-associated proteins (including Cntnap2 and Cntnap3) that form the synaptic scaffolding system and are involved in trans-synaptic communication. Similarly to downregulated genes, alternative splicing events involved proteins that are important for synaptic signaling (Table 1 and Supplementary Table 4). For example, we observed increased skipping of alternative exons in Scrib, a gene encoding a protein involved in neurotransmitter release (Fig. 5b). We also confirmed differential splicing of Exon 7 in Apbb2, a protein involved in synaptic vesicle loading (Fig. 5b). We noted altered splicing amongst members of neurexins, synaptic receptors that undergo an extensive combinatorial use of AS to provide molecular diversity required for the functional differentiation of synapses (Supplementary Table S1) ${ }^{43}$. Finally, we observed, AS events in proteins involved in the synaptic vesicle cycle, including both pre-synaptic and post-synaptic space, amongst them Stx4A, Syn1, Synj1, Stx3 and many others, some of them resulting in premature termination codons, 
Maslon et al.

others changing domain structures or affecting ion transfer, hence all likely contributing to the function or the specificity of the synapse (Table 1).

Interestingly, we noticed that those genes that are preferentially downregulated and/or alternatively spliced in slow/slow neurons, tend to be significantly longer than those that were not affected or that are upregulated (Fig. 6b, right panel). By, contrast, we found no significant change in the average gene length between downregulated genes and all expressed genes in ESCs or NPCs (Fig. 6b, left panel and data not shown). Notably, a slow transcriptional elongation rate reduced expression of nearly all long genes in neurons, with the percentage of downregulated genes in slow/slow neurons progressively increasing from around $40 \%$ for $10 \mathrm{~kb}$ genes to over $80 \%$ for extremely long genes (Fig. 6c). Some examples of such genes include Cntnap2 (2.25 Mb) and Nrxn1 (1.05 Mb) (Supplementary Table 2). Similarly, AS also affected longer premRNAs (Fig. 6b). From this we speculate that an optimal elongation rate is important to sustain transcription and splicing of particularly long transcripts that are required for neuronal function. Indeed, recent reports propose that long genes require special mechanisms to specifically maintain long-distance transcription. As an example, the neuronal RNA-binding protein Sfpq (proline/glutamine-rich, also known as PSF), has been shown to be a critical factor for maintaining transcriptional elongation of long genes $^{44,45}$.

Thus, we found that both downregulated as well as preferentially alternatively spliced genes in slow/slow ESC-derived neurons converged onto long genes that are involved in synaptic function. Candidate genes involved in neurodevelopmental diseases encode synapse proteins and are exceptionally long ${ }^{46}$. We identified synapse signaling as a major pathway downregulated and mis-spliced in slow/slow neurons and found that slow RNAPII downregulated almost all long genes in neurons. Therefore, we further 


\section{Maslon et al.}

analyzed the overlap of the genes downregulated and differentially spliced in slow/slow neurons with available datasets for brain disease, including causative genes for autism and schizophrenia (SFARI). We noted that genes differentially expressed and spliced in slow/slow neurons significantly overlapped with those linked to neurological disorders, including ASD disease (Supplementary Table 5). From these experiments, we can conclude that a reduced transcriptional elongation rate preferentially affects the expression and alternative splicing of long synaptic genes.

In summary, the development of a genetic system based on knock-in for a slow RNAPII mutation in mouse ESCs unequivocally established that an appropriate RNAPII elongation rate is essential for proper mouse development and for gene expression and its kinetic coupling with AS. Interestingly, the kinetic control of AS is predominantly affected in differentiated cells, suggesting that the chromatin environment represents an important determinant of this coupling. Altogether, our results provide compelling evidence that transcription elongation rates can have a regulatory role in the expression of genes and the regulation of their alternative splicing patterns during development. 
Maslon et al.

\section{Discussion}

We observed that a slow RNAPII mutant caused embryonic lethality even in heterozygosity (Fig. 2). It is possible that a slow elongation rate cannot sustain the high levels of mRNA production required at early stages of development ${ }^{47,48}$. Similarly, loss of self-renewal in slow/slow NSCs could be related to the inability of cells harboring a slow RNAPII to maintain the required levels of transcriptional output. Initial stages of mouse embryonic development display a great range of cell cycle duration, from up to 20 hours for the first cell division to $2-3$ hours cell cycles during gastrulation ${ }^{49}$ or 8 hours during initial stages of murine neurogenesis ${ }^{50}$. Thus, a reduced elongation rate in slow/slow mutant embryos might not allow efficient transcription or might delay expression of some crucial mRNAs that need to be expressed in these fast dividing cells. Whereas in mice both the homozygous and heterozygous slow mutation result in embryonic lethality (Fig. 2), the C4 mutation in Drosophila is tolerated in heterozygosity where the flies present a mutant phenotype called "Ubx effect" that resembles the one seen in flies haploinsufficient for the Ubx protein. This was attributed to Ubx missplicing as it is one of the few Drosophila genes with an extremely long intron $(50 \mathrm{~kb})^{10}$. This is in agreement with results presented here showing that mouse genes with long introns are preferentially affected by a slow RNAPII in ESCdifferentiated neurons.

The slow RNAPII mutant used in this study is less efficient at dealing with naturally occurring pause sites in vivo ${ }^{10,12}$. We found that the impact of RNAPII elongation rate on AS is predominant in ESCs-differentiated NPCs and neurons. This is likely caused by distinct chromatin environment between pluripotent and differentiated cells having a differential impact on RNAPII transcriptional elongation rate. While chromatin is quite dispersed in E3.5, heterochromatin foci appear in E5.5, which corresponds to the 
epiblast stage following embryo implantation ${ }^{51}$. Indeed, despite the conflicting literature regarding deposition of histone marks throughout differentiation ${ }^{52-54}$, a large body of evidence suggests that chromatin undergoes dynamic changes during differentiation leading to a more compact environment in the differentiated state. Various mechanisms might promote the switch from a more open to a more close chromatin during cell differentiation, including an increase in repressive histone marks, a local change in nucleosome occupancy, or a general increase in histones levels ${ }^{55,56}$. Indeed, the nuclei of ESCs macroscopically appears to contain less condensed chromatin, whereas well-defined foci of compact heterochromatin become evident in ESCs-derived $\mathrm{NPCs}^{57}$. Indeed, chromatin structure can become a major impediment to transcriptional elongation and histone modifications can directly affect the nucleosomes, by either loosening or tightening DNA binding around them ${ }^{58,59}$. Moreover, exons have a negative effect on RNAPII elongation rate, which could be associated with exonic features, such as a higher CG content, and exon-specific histone marks (H3K36me3 and H3K4me1) ${ }^{26}$. An example of a crosstalk between the chromatin environment an AS has been shown in the case of exon18 in the neural cell adhesion molecule (NCAM), where membrane depolarization of neuronal cells induces a local H3K9 hyperacetylation, resulting in exon skipping ${ }^{60}$. Conversely, inducing a more compact chromatin state by transfection of siRNAs targeting the intron downstream of an alternative exon, promotes $\mathrm{H} 3 \mathrm{~K} 9$ and $\mathrm{H} 3 \mathrm{~K} 27$ methylation, $\mathrm{HP} 1$ recruitment, in turn leading to local roadblocks for RNAPII elongation rate and increased kinetic coupling $^{61}$. We speculate that the specific changes in chromatin structure during differentiation might create natural "roadblocks" to elongating RNAPII, which is further enhanced in slow RNAPII-expressing cells leading to increased kinetic coupling observed in NPCs and neurons derived from slow/slow cells. 
Slow RNAPII leads to specific downregulation of longer genes in neurons. Dysregulation of the expression of these long genes might represent a mechanism underlying neurodegenerative and psychiatric disorders ${ }^{62,63}$. For example, loss of FUS/TLS and TDP43, genes linked to ALS, preferentially affects splicing of long premRNAs $^{64}$. The neuronal RBP SFPQ, which is required to sustain long-distance transcription elongation for longer genes ${ }^{45}$, has a role in neurodegenerative diseases, including ALS, ASD and Frontotemporal lobar degeneration (FTLD). The differentially expressed and alternatively spliced pre-mRNAs in neurons are involved in synapse signaling, neurite outgrowth and axonal guidance. We speculate that misregulation of RNAPII elongation rate could have detrimental implication in neurodevelopment, preferentially affecting the expression and/or splicing of synaptic proteins, which are encoded by particularly long genes (Fig. 6). Indeed mutations in genes involved in synaptic signaling lead to neurodevelopmental diseases, including Autism spectrum disorder (ASD) ${ }^{46}$. Importantly, chromatin remodeling, transcription and splicing genes have been identified in genetics studies of de novo mutations in autistic patients ${ }^{65}$. Physiological conditions that could alter RNAPII elongation or mutations disrupting elongation rate control might affect preferentially the nervous system, as these cells express particularly long genes. This could result not only in changes in transcription but also affect AS patterns via kinetic coupling. These observations highlight an essential role for an appropriate elongation rate in gene expression and splicing regulation during neural development and suggest that its misregulation could underlie some neurological disorders. In conclusion, we show that a slow elongation rate affects gene expression and AS, consistent with the coupling of transcription with splicing. This kinetic control of AS is more strongly affected as differentiation progress. Most notably, we identify elongation rate control as a major 
mechanism to sustain transcription and splicing of long neuronal genes involved in synapse signaling. This study provides a compelling evidence that transcription elongation rates have a regulatory role in the expression of genes and the regulation of their AS patterns during development.

\section{Methods}

Methods, including statements of data availability and any associated codes and references, are available in the online version of the paper.

Note: Any Supplementary Information and Source Data files are available in the online version of the paper.

\section{Acknowledgments}

We are grateful to Nick Hastie (MRC HGU) and Wendy Bickmore (MRC HGU) for support at the initial stages of this project. We thank Graeme Grimes (MRC HGU) for help with bioinformatics analysis. We thank Wendy Bickmore (MRC HGU) for critical reading of the manuscript. We acknowledge the contributions of David Read, who recently passed away. This work was supported by Core funding from the Medical Research Council (J.F.C and I.A) and by a Wellcome Trust Investigator Award (Grant R to J.F.C).

\section{Author contributions}

M.M.M., I.R.A and J.F.C. conceived, designed and interpreted the experiments. U.B. and B.J.B. provided bioinformatics analysis and discussion of AS changes during differentiation. S.A contributed to the bioinformatics analysis of RNAPII elongation rates A.R.W., C.H. and F.K. carried out ESCs targeting. The CBS Transgenic Core 
bioRxiv preprint doi: https://doi.org/10.1101/426577; this version posted November 4,2018 . The copyright holder for this preprint (which was not certified by peer review) is the author/funder, who has granted bioRxiv a license to display the preprint in perpetuity. It is made available under aCC-BY-NC-ND 4.0 International license.

Maslon et al.

performed CRISPR injections and mouse work. A.R.K participated in discussions.

M.M.M., B.J.B, A.R.K., I.R.A and J.F.C. wrote the paper.

Competing financial interests: The authors declare that they have no competing financial interests 
Maslon et al.

\section{Figure legends}

Fig. 1 | Generation of slow RNAPII knock-in mutant mouse ESCs. a, Cartoon depicting the mutagenesis strategy, including the genomic target locus, as well as the structure of targeting vector. Arrows indicate location of primers used for genotyping. b, Restriction enzyme diagnostic test for the presence of the R749H mutation. c, Sequence trace of cDNA showing the presence of the heterozygous and homozygous R749H mutation. d, qRT-PCR with primers specific to both wild-type and mutant RNAPII (left panel) or to the mutant form of RNAPII (right panel), confirming that only the slow version of RNAPII is expressed in homozygous slow/slow ESCs.

Fig. 2 | CRISPR/Cas-mediated generation of a slow RNAPII knock-in mutant mouse. a, Cartoon depicting the mutagenesis strategy, including the genomic target locus, as well as two repair templates, either introducing a silent mutation (silent oligo) or the R749H mutation (slow oligo). Multiple repair oligo templates were tested with different composition of silent restriction sites. $\mathbf{b}$ and $\mathbf{c}$, Total number of WT, heterozygous and homozygous embryos (E3.5 and E9.5), as well as born mice from several targeting experiments introducing either the slow $(\mathrm{R} 749 \mathrm{H})$ RNAPII mutation or repaired with the WT sequence (silent oligo). Repair oligos and the stage that embryos/mice were analyzed are indicated.

Fig. 3 | Global analysis of transcription elongation rate in mouse ESCs by 4sU-DRBseq. a, Schematic of the 4sU-DRB-seq labeling protocol. b, Meta-gene profile of normalized 4sU-DRB-seq reads in WT/WT and slow/slow ESCs. c-d, Density and box plot of elongation rate (bases/min) calculated for genes common in all genotypes in WT/WT, 
Maslon et al.

WT/slow and slow/slow ESCs. Box and whisker (5-95 percentile) indicates median. Mann-Whitney test, $\mathrm{p}<0.0001$.

Fig. 4 a, Schematic of the neural differentiation system used in this study. b, Brightfield images and analysis of NPC markers by immunofluorescence staining (Sox1 and Nestin) or RT-qPCR (Nestin and Pax6) (n=3, mean \pm SEM). c, Brightfield images of aggregates. d, Brightfield images and immunofluorescence staining for Nestin and neuronal marker Tuj1. White arrows indicate NSCs and green arrows differentiated cells. Two small panels on the right are examples of Tuj1+ neuronal cells in slow/slow NSCs cultures. e, Immunofluorescence staining for neuronal marker Tuj1 at 21 days of differentiation.

Fig. 5 | The rate of transcriptional elongation influences alternative splicing decisions in ESCs and during neural differentiation. a, Number of alternative splicing events that are sensitive to a slow elongation rate, including cassette exons, microexons, alternative 3' or 5' splice sites and retained introns in ESCs and at different stages of neural differentiation. UP and DOWN refers to increased or decreased levels of a splicing event in slow/slow cells relative to WT cells. Only events that are significantly different $($ FDR $<0.05)$ with dPSI (percent spliced in) $\geq 10 \%$ were considered. $\mathbf{b}$, RT-PCR analysis validation of selected alternatively spliced exons. RT PCR was performed on total RNA from WT or slow/slow ESCs, NPCs or neurons. PCR products were visualized and quantified by Bioanalyzer (Agilent).

Fig. 6 | A slow RNAPII preferentially affects synaptic genes. a, Gene ontology analysis of genes downregulated in slow/slow neurons showing the top ranked cellular 
bioRxiv preprint doi: https://doi.org/10.1101/426577; this version posted November 4,2018 . The copyright holder for this preprint (which

was not certified by peer review) is the author/funder, who has granted bioRxiv a license to display the preprint in perpetuity. It is made available under aCC-BY-NC-ND 4.0 International license.

\section{Maslon et al.}

component (CC), biological processes (BP) or molecular functions (MF) GO categories. b, Box plot showing the length of upregulated (UP), downregulated (DOWN), not affected genes (ALL), and pre-mRNAs affected by alternative splicing (AE, for Alternative exons) for ESCs (left panel); length of upregulated (UP), downregulated (DOWN), not affected genes (ALL), pre-mRNAs affected by alternative splicing (AE, for Alternative exons), and not affected genes that are only expressed in neurons (but not in ESCs) (ALL_notESC), for Neurons (right panel). c, Percentage of genes that are downregulated in neurons; plotted as a sliding window of 100 genes by length. 
Maslon et al.

\section{Methods}

Ethical statement. All applicable international, national and institutional guidelines for the care and use of animals were followed. Animal experiments were carried out under UK Home Office Project Licences PPL 60/4424 and PB0DC8431 and were approved by the University of Edinburgh animal welfare and ethical review body.

Gene targeting in ESCs. The bacterial artificial chromosome (BAC) bMQ420i24 containing chr11:69711833-69860134 (mm10 assembly) of the mouse genome from 129S7/SvEvBrd ES cells ${ }^{66}$ was modified to introduce the R749H mutation into exon 14 of Polr $2 a$ using a GalK selection cassette as described ${ }^{67}$. A $\sim 10.3 \mathrm{~kb}$ region (chr11:69741333-69751734) of the Polr2a locus was then retrieved into the NotI-SpeI region of PL253 using gap repair, and a Frt-flanked neomycin resistance cassette from plasmid PL451 introduced into intron 12 of the gap-repaired Polr $2 a$ clone at position chr11:69743748-69743749 as described ${ }^{68}$. The resulting targeting vector was linearized with NotI and introduced into E14 ESCs by electroporation ${ }^{69}$. Genomic DNAs from were screened for homologous recombination by PCR. The neomycin resistance cassette was then excised by electroporation with an Flp recombinase expression plasmid to generate WT/slow heterozygous ESCs. The same targeting vector was used to target the WT Pol2ra allele in the WT/slow ESCs, and the neomycin resistance cassette excised using Flp recombinase in order to generate slow/slow ESCs. WT/WT, WT/slow and slow/slow ESCs were confirmed to contain forty chromosomes by karyotyping as described ${ }^{70}$. Ion Torrent sequencing of overlapping PCR products from ESC genomic DNA encompassing a $\sim 14 \mathrm{~kb}$ region around the R749H mutation (chr11:69739041-69753349) was used to confirm that the WT/slow and slow/slow ESCs contained no genomic re-arrangements or additional mutations in this region 
relative to the parental WT/WT ESCs. Genotyping was performed using the following forward and reverse primers: GGGACTCCATTGCAGATTC and ACTCAGTGGGTGTGAGACC.

Mice Chimaera generation and breeding. In order to generate mouse chimaeras, WT/slow ESCs were injected into C57BL/6 host chimaeras, as previously described ${ }^{69}$. Eight male chimaeras with at least $30 \%$ contribution from ESCs were identified by coat colour and bred with $\mathrm{C} 57 \mathrm{BL} / 6$ females to test for germline transmission.

CRISPR/Cas9 Gene Editing in Mouse Zygotes. Complementary oligonucleotides targeting exon 14 of Polr $2 a$ were annealed and cloned into plasmid pX335 ${ }^{71}$. The guide region was then amplified by PCR and paired guide RNAs synthesised by in vitro transcription (T7 Quick High Yield RNA Synthesis kit, NEB). Single stranded DNA oligonucleotides (silent oligo: TCATTGAGAAGGCTCATAACAATGAGCTA GAACCCACTCCAGGAAACACATTGAGACAAACATTTGAGAATCAAGTGA ATCGTATTCTCAATGATGCTAGGGACAAAACTGGCTCCTCTGCACAGAAA TCCCTCTCTGAATATAACAACTTCAAGTCTTGGTGGTGTCTGGAGCCAAGG GTTCCAAGATCAACATCTCC, slow oligo: TCATTGAGAAGGCTCATAACAAT GAGCTAGAACCCACTCCAGGAAACACATTGAGACAAACATTTGAGAATCA AGTGAATCGTATTCTCAATGATGCTCATGACAAAACTGGCTCCTCTGCACA GAAATCCCTCTCTGAATATAACAACTTCAAGTCTATGGTGGTGTCTGGAGC CAAGGGTTCCAAGATCAACATCTCC) were synthesised by IDT. Gene editing was performed by microinjection of RNA encoding the Cas9 nickase mutant ( $50 \mathrm{ng} / \mu \mathrm{l}$, TriLink BioTechnologies), paired guide RNAs (each at $25 \mathrm{ng} / \mu \mathrm{l}$ ), and $150 \mathrm{ng} / \mu \mathrm{l}$ singlestranded DNA oligonucleotide repair template in (C57BL/6 x CBA) F2 zygotes ${ }^{72}$, and 
Maslon et al.

the injected zygotes were cultured overnight in KSOM for subsequent transfer to the oviduct of pseudopregnant recipient females ${ }^{69}$, or for three days to allow analysis of morula/blastocyst stage embryos. CRISPR/Cas9 gene editing can generate mosaic embryos $^{73}$, but for simplicity embryos that were genotyped to contain both a wild-type and a mutant Polr2a allele were classified as heterozygotes. Genotyping was performed as above except for blastocysts genotyping where nested PCR was performed, using first the above forward and reverse primers, followed by second PCR using the following forward and reverse primers: GAAGGCTGGGCAGAGAAGAG and TCCGCTTGCCCTCTACATTC

In vitro transcription assay. Nuclear extracts were prepared, as previously described $^{74}$. A DNA construct, containing CMV promoter and encoding $\beta$-globin was linearized by restriction digest. In vitro transcription reactions were performed at $30^{\circ} \mathrm{C}$ in $25 \mu 1$ reaction mixtures containing 375 ng DNA template, $1 \mu 1$ 32P-UTP, $10 \mu 1$ ESCs nuclear extract, $10 \mathrm{mM}$ ATP, CTP, GTP, $0.4 \mathrm{mM}$ UTP, $3.2 \mathrm{mM} \mathrm{MgCl2}$. Following indicated time, proteinase $\mathrm{K}$ was added to stop transcription. RNA was extracted and run on denaturing polyacrylamide gel and detected by phosphoimager.

Nascent transcription assays. Elongation rate experiments were carried out as described $^{23}$. Briefly, cells were treated for 4 hr with $100 \mu \mathrm{M}$ 5,6-dichlorobenzimidazole 1- $\beta$-d-ribofuranoside (DRB) to inhibit transcription. To restart transcription, cells were washed twice in war, PBS, and incubated with fresh medium. During 0-180 min incubation, at indicated times, cells were lysed directly in Trizol and RNA was extracted according to manufacturer's recommendations. $5 \mu \mathrm{g}$ of Total RNA were reverse transcribed using random hexamers and Superscript III. Pre-mRNA levels were 
measured by quantitative RT-PCR using Sybr Green Master Mix and Lightcycler 480 (Biorad). Primers used in the quantitative RT-PCR are available on request. Pre-mRNA levels were normalised to pre-mRNA levels at $\mathrm{t}=0 \mathrm{~min}$. Results depict average of three independent experiments, \pm standard error.

4sU-DRBseq. ESCs were seeded in $15-\mathrm{cm}$ plates in $2 \mathrm{i}$ medium. At the $80-90 \%$ confluency, cells were treated with $100 \mu \mathrm{M}$ DRB. Following 4 hours of incubation, DRB-containing media was removed, cells were washed twice with warm PBS and placed in fresh media without DRB. 4-thiouridine $(4 \mathrm{sU})$ was added to medium at a final concentration of $1 \mathrm{mM}$ for 10 minutes before each harvest. Cells were lysed directly on a plate with $5 \mathrm{ml}$ of Trizol at indicated transcription elongation time point. Total RNA was isolated as per manufacturer's instructions. Total RNA (100-200 $\mu \mathrm{g})$ was used for biotinylation and purification of $4 \mathrm{sU}$-labeled nascent RNAs. The biotinylation reaction consisted of total RNA and EZ-Link Biotin-HPDP dissolved in dimethylformamide (DMF) and was performed in labeling buffer (10 mM Tris $\mathrm{pH} 7.4,1 \mathrm{mM}$ EDTA) for 2 hours with rotation at room temperature. Unbound Biotin-HPDP was removed by chloroform/isoamylalcohol (24:1) extraction in MaXtract tubes (Qiagen). RNA was precipitated with $10^{\text {th }}$ volume of $5 \mathrm{M} \mathrm{NaCl}$ and 1 volume of isopropanol. Following one wash in $80 \%$ ethanol, the RNA pellet was left to dry and resuspended in $100 \mu 1$ RNasefree water. Biotinylated RNA was purified using $\mu$ Macs Streptavidin kit. Specifically, $100 \mu \mathrm{l}$ of beads per $100 \mu \mathrm{g}$ of RNA was incubated with rotation for $15 \mathrm{~min}$, and then washed three times with washing buffer (100 mM Tris $\mathrm{pH} 7.5,10 \mathrm{mM}$ EDTA, $1 \mathrm{M}$ $\mathrm{NaCl}, 0.1 \%$ Tween 20 ) at $65^{\circ} \mathrm{C}$, followed by three washes at room temperature. RNA was eluted twice using 100 mM DTT and recovered using RNeasy MinElute Cleanup column (Qiagen) according to instructions. cDNA libraries were prepared using NEB 
Maslon et al.

Next Ultra Directional RNA Library Prep Kit according to the manufacturer's instructions. Libraries were pooled and sequenced on an Illumina HiSeq 4000 system. All reads were aligned to the mouse reference genome (mm10) using bowtie 2 aligner $^{75}$ and only those reads that mapped uniquely to the genome, but not to rRNA, were considered. A genome-wide binned profile of the nascent RNA and the transcription wave end were determined using previously developed methods and published software 28,76 .

Cell differentiation. ESCs were cultured under feeder-free conditions in GMEM medium supplemented with $10 \%$ fetal calf serum, NEAA, $\beta$-mercaptoethanol, sodium pyruvate, L-glutamine and $100 \mathrm{U} / \mathrm{ml}$ recombinant leukaemia inhibitory factor (LIF) on gelatin-coated tissue culture plastic. Before differentiation, cells were freshly defrosted in standard medium and then passaged for 2 passages in $2 \mathrm{i}$ medium (1:1 Neurobasal and DMEM/F12, supplemented with 0.5X N2, 0.5x B27, 0.05\% BSA, $1 \mu \mathrm{M} 0325901$, 3 $\mu \mathrm{M}$ CHIR99021, 2mM L-glutamine, 0.15mM monothioglycerol, 100U/ml LIF).

Neuroectodermal specification. One day prior to induction of differentiation cells were seeded at high density in $2 \mathrm{i}$ medium. The following day, cells were detached using accutase, resuspended in N2B27 media (1:1 Neurobasal and DMEM/F12, supplemented with $0.5 \mathrm{X}$ N2, 0.5x B27, $0.1 \mathrm{mM} \beta$-mercaptoethanol, $0.2 \mathrm{mM} \mathrm{L-}$ glutamine), counted and plated at the appropriated density onto either $15 \mathrm{~cm}$ plates or 6 well plates that have been coated with a $0.1 \%$ gelatin solution. Culture medium was changed every second day. The differentiation potential is greatly influenced by the initial plating density and was previously established to be optimal at approximately 10,000 cells per $\mathrm{cm}^{2}$, which is what we observed with the differentiation of WT ESCs. 
On the contrary, we observed increased cell death at plating densities below 30,000 cells per $\mathrm{cm}^{2}$ for slow/slow cells, suggesting decreased proliferation or compromised differentiation potential of these cells.

Deriving NS cells. For derivation of neural stem cells at day 7 of differentiation, cultures were detached using accutase, 2-3 x $10^{6}$ cells were re-plated into an uncoated T75 flask in NS expansion media, comprising DMEM/F12 medium supplemented with 2mM L-glutamine, $0.5 \mathrm{x}$ N2, B27, glucose, BSA, Hepes and 10ng/ml of both mouse EGF (Peprotech) and human FGF-2 (Peprotech). Within 2-3 days, thousands of cell aggregates formed in suspension culture and were harvested by centrifugation at 700 rpm for 1 minute. They were then re-plated onto a laminin coated T75 flask. After few days, cell aggregates attached to the flask and outgrew with NS cell.

Differentiation to neurons. For neuronal generation and maturation at day 7 of differentiation, cultures were detached using accutase, replated onto poly-1ornithine/laminin $(100 \mu \mathrm{g} / \mathrm{ml}$ and $10 \mu \mathrm{g} / \mathrm{ml}$, respectively, Sigma-Aldrich) coated surfaces at $1.5-2 \times 10^{4}$ cells/ $\mathrm{cm}^{2}$ in $\mathrm{N} 2 \mathrm{~B} 27$ medium containing $0.2 \mathrm{mM}$ ascorbic acid and $0.25 \mathrm{mM}$ cAMP. Cells were grown for the additional 7 days, with $80 \%$ media exchange every second day.

RNA isolation and RT-QPCR. RNA was isolated using TRIzol or RNAeasy following the manufacturer's protocol. RNA was then treated with Dnase (Ambion) and transcribed to cDNA using First-Strand Synthesis System from Roche. This was followed by SybrGreen detection system (Lightcycler 2x SybrGreen Mix, Roche). 
RNA-Seq analysis. RNA-Seq libraries were generated from Poly $(\mathrm{A})^{+}$mRNA and sequenced using the Illumina Hi-Seq 2500 or 4000 machine to generate 125 bases or 75 bases, paired end reads, respectively. Reads were mapped to the mouse (mm9) genome. AS analysis of RNA-Seq data was performed with vast-tools version $1^{77}$. From the primary output, events with poor coverage or junction balance were filtered out (vast-tools quality score 3 other than $\mathrm{SOK} / \mathrm{OK} / \mathrm{LOW}$ for cassette exon [CE], microexon [MIC], and alternative $5^{\prime}$ or $3^{\prime}$ splice site [Alt5/3] events or coverage less than 15 reads for intron retention [IR] events; score 4 other than OK/B1 for CE and MIC events and score 5 of less than 0.05 for IR events). Differential AS was scored using vast-tool's diff module requiring $\mathrm{p}(|\mathrm{dPSI}|>0)>0.05$ and a point estimate of $|\mathrm{dPSI}|>10$. Gene expression was analysed based on raw read counts per gene from vast-tools using the glm stream of the $\mathrm{R}$ package edgeR. Genes with an FDR $<0.05$ were considered differentially expressed.

Networks. The GO network for the genes misregulated in cells harboring slow RNAPII was built using Enrichment Map ${ }^{78}$ in Cytoscape 3.3.1 ${ }^{79}$ with the following parameters: p-value cut-off $=0.001 ;$ FDR $Q$ value cut-off $=0.01$; Jaccard + Overlap Combined option, with cut-off $=0.375$; Combined Constant $=0.5$. Enriched functional terms were obtained from g:profiler or by GSEA for GO_BP and KEGG pathways. g:profiler was employed for the analysis of GO enrichment during neuronal differentiation. 
Maslon et al.

\section{Key reagents table}

\begin{tabular}{|c|c|c|}
\hline REAGENT & MANUFACTURER & CATALOG NUMBER \\
\hline \multicolumn{3}{|l|}{ Antibodies } \\
\hline Tuj1 & BioLegend & MMS-435P \\
\hline Map2 & Millipore & MAB3418 \\
\hline RNAPII (8WG16) & Abcam & ab817 \\
\hline Syn1 & Novus Biologicals & NB300-104 \\
\hline Tubulin & Sigma & T9026 \\
\hline Nestin & Abcam & $\mathrm{Ab} 24692$ \\
\hline \multicolumn{3}{|l|}{ Chemicals } \\
\hline $\begin{array}{l}\text { 5,6-dichlorobenzimidazole } \\
\text { 1- } \beta \text {-d-ribofuranoside } \\
\text { (DRB) }\end{array}$ & Sigma-Aldrich & D1916 \\
\hline 4-thiouridine & Sigma-Aldrich & T4509 \\
\hline EZ-Link biotin HPDP & Thermo Scientific & 21341 \\
\hline Dimethylformamide & Thermo Scientific & 20673 \\
\hline $\begin{array}{l}\text { No-Weigh dithiothreitol } \\
\text { (DTT) microtubes }\end{array}$ & Thermo Scientific & 20291 \\
\hline \multicolumn{3}{|c|}{ Cell culture reagents, cytokines } \\
\hline Recombinant Murine EGF & Peprotech & $315-09$ \\
\hline $\begin{array}{l}\text { Recombinant Human FGF- } \\
\text { basic }\end{array}$ & Peprotech & $100-18 B$ \\
\hline Ascorbic Acid & Stemcell Technologies & 07157 \\
\hline Dibutyryl-cAMP & Stemcell Technologies & 73886 \\
\hline DMEM/F12 & Thermo Scientific & 31331028 \\
\hline Neurobasal medium & Thermo Scientific & 21103049 \\
\hline GMEM & Thermo Scientific & \\
\hline \multicolumn{3}{|l|}{$\begin{array}{l}\text { MEM Non-essential amino } \\
\text { acid }\end{array}$} \\
\hline \multicolumn{3}{|l|}{ Sodium pyruvate } \\
\hline \multicolumn{3}{|l|}{ 2-mercaptoethanol } \\
\hline BSA $(7.5 \%$ solution $)$ & Thermo Scientific & 15260037 \\
\hline N-2 Supplement (100x) & Thermo Scientific & 17502048 \\
\hline B-27 Supplement (50x) & Thermo Scientific & 17504044 \\
\hline PD0325901 & Stemcell Technologies & 72182 \\
\hline CHIR99021 & Miltenyi Biotec & $130-103-926$ \\
\hline $\begin{array}{l}\text { Poly-DL-ornithine } \\
\text { hydrobromide,mol wt } \\
3,000-15,000\end{array}$ & Sigma-Aldrich & P8638 \\
\hline \multicolumn{3}{|l|}{ Commercial Assays and Kits } \\
\hline $\begin{array}{l}\text { RNeasy MinElute clean-up } \\
\text { kit }\end{array}$ & Qiagen & 74204 \\
\hline$\mu$ Macs Streptavidin Kit & Miltenyi & 130-074-101 \\
\hline Turbo DNase & Ambion & \\
\hline $\begin{array}{l}\text { NEBNext Ultra II } \\
\text { Directional RNA Library } \\
\text { Prep Kit for Illumina }\end{array}$ & $\mathrm{Neb}$ & E7420 \\
\hline
\end{tabular}


Maslon et al.

\begin{tabular}{|l|l|l|}
\hline $\begin{array}{l}\text { NEBNext Multiplex } \\
\text { Oligos }\end{array}$ & Neb & E7335, E7500 \\
\hline
\end{tabular}

\section{References}

1. Schwartz, S. \& Ast, G. Chromatin density and splicing destiny: on the crosstalk between chromatin structure and splicing. EMBOJ. 29, 1629-36 (2010).

2. Naftelberg, S., Schor, I. E., Ast, G. \& Kornblihtt, A. R. Regulation of Alternative Splicing Through Coupling with Transcription and Chromatin Structure. Annu. Rev. Biochem. 84, 165-198 (2015).

3. Beyer, A. L. \& Osheim, Y. N. Splice site selection, rate of splicing, and alternative splicing on nascent transcripts. Genes Dev. 2, 754-65 (1988).

4. Roberts, G. C., Gooding, C., Mak, H. Y., Proudfoot, N. J. \& Smith, C. W. Cotranscriptional commitment to alternative splice site selection. Nucleic Acids Res. 26, 5568-72 (1998).

5. Suñé, C. \& Garcia-Blanco, M. A. Transcriptional cofactor CA150 regulates RNA polymerase II elongation in a TATA-box-dependent manner. Mol. Cell. Biol. 19, 4719-28 (1999).

6. Lin, S., Coutinho-Mansfield, G., Wang, D., Pandit, S. \& Fu, X.-D. The splicing factor SC35 has an active role in transcriptional elongation. Nat. Struct. Mol. Biol. 15, 819-26 (2008).

7. Herzel, L., Ottoz, D. S. M., Alpert, T. \& Neugebauer, K. M. Splicing and transcription touch base: co-transcriptional spliceosome assembly and function. Nat. Rev. Mol. Cell Biol. 18, 637-650 (2017).

8. Aslanzadeh, V., Huang, Y., Sanguinetti, G. \& Beggs, J. D. Transcription rate strongly affects splicing fidelity and cotranscriptionality in budding yeast. Genome Res. 28, 203-213 (2018).

9. Bentley, D. L. Coupling mRNA processing with transcription in time and space. Nat. Rev. Genet. 15, 163-75 (2014).

10. de la Mata, M. et al. A Slow RNA Polymerase II Affects Alternative Splicing In Vivo. Mol. Cell 12, 525-532 (2003).

11. Dujardin, G. et al. How Slow RNA Polymerase II Elongation Favors Alternative Exon Skipping. Mol. Cell 54, 683-90 (2014).

12. Fong, N. et al. Pre-mRNA splicing is facilitated by an optimal RNA polymerase II elongation rate. Genes Dev. 28, 2663-76 (2014).

13. Eperon, L. P., Graham, I. R., Griffiths, A. D. \& Eperon, I. C. Effects of RNA secondary structure on alternative splicing of pre-mRNA: is folding limited to a region behind the transcribing RNA polymerase? Cell 54, 393-401 (1988).

14. Buratti, E. \& Baralle, F. E. Influence of RNA secondary structure on the premRNA splicing process. Mol. Cell. Biol. 24, 10505-14 (2004). 
Maslon et al.

15. Saldi, T., Fong, N. \& Bentley, D. L. Transcription elongation rate affects nascent histone pre-mRNA folding and 3' end processing. Genes Dev. 32, 297308 (2018).

16. Ip, J. Y. et al. Global impact of RNA polymerase II elongation inhibition on alternative splicing regulation. Genome Res. 21, 390-401 (2011).

17. Muñoz, M. J. et al. DNA damage regulates alternative splicing through inhibition of RNA polymerase II elongation. Cell 137, 708-20 (2009).

18. Williamson, L. et al. UV Irradiation Induces a Non-coding RNA that Functionally Opposes the Protein Encoded by the Same Gene. Cell 168, 843855.e13 (2017).

19. Coulter, D. E. \& Greenleaf, A. L. A mutation in the largest subunit of RNA polymerase II alters RNA chain elongation in vitro. J. Biol. Chem. 260, 131908 (1985).

20. Mortin, M. A., Kim, W. J. \& Huang, J. Antagonistic interactions between alleles of the RpII215 locus in Drosophila melanogaster. Genetics 119, 863-73 (1988).

21. Chen, Y., Chafin, D., Price, D. H. \& Greenleaf, A. L. Drosophila RNA polymerase II mutants that affect transcription elongation. J. Biol. Chem. 271, 5993-9 (1996).

22. BVAAWF/FRAME/RSPCA/UFAW Joint Working Group on Refinement. Refinement and reduction in production of genetically modified mice. $L a b$. Anim. 37 Suppl 1, S1-S49 (2003).

23. Singh, J. \& Padgett, R. A. Rates of in situ transcription and splicing in large human genes. Nat. Struct. Mol. Biol. 16, 1128-1133 (2009).

24. Boireau, S. et al. The transcriptional cycle of HIV-1 in real-time and live cells. J. Cell Biol. 179, 291-304 (2007).

25. Danko, C. G. et al. Signaling pathways differentially affect RNA polymerase II initiation, pausing, and elongation rate in cells. Mol. Cell 50, 212-22 (2013).

26. Jonkers, I., Kwak, H. \& Lis, J. T. Genome-wide dynamics of Pol II elongation and its interplay with promoter proximal pausing, chromatin , and exons. 1-25 (2014). doi:10.7554/eLife.02407

27. Rädle, B. et al. Metabolic Labeling of Newly Transcribed RNA for High Resolution Gene Expression Profiling of RNA Synthesis, Processing and Decay in Cell Culture. J. Vis. Exp. e50195-e50195 (2013). doi:10.3791/50195

28. Fuchs, G. et al. 4sUDRB-seq: measuring genomewide transcriptional elongation rates and initiation frequencies within cells. Genome Biol. 15, R69 (2014).

29. Doe, C. Q. Neural stem cells: balancing self-renewal with differentiation. Development 135, 1575-87 (2008).

30. Aguirre, A., Rubio, M. E. \& Gallo, V. Notch and EGFR pathway interaction regulates neural stem cell number and self-renewal. Nature 467, 323-327 (2010). 
31. Ying, Q.-L., Stavridis, M., Griffiths, D., Li, M. \& Smith, A. Conversion of embryonic stem cells into neuroectodermal precursors in adherent monoculture. Nat. Biotechnol. 21, 183-186 (2003).

32. Conti, L. et al. Niche-Independent Symmetrical Self-Renewal of a Mammalian Tissue Stem Cell. PLoS Biol. 3, e283 (2005).

33. Chanda, S. et al. Generation of induced neuronal cells by the single reprogramming factor ASCL1. Stem cell reports 3, 282-96 (2014).

34. Gkikas, D., Tsampoula, M. \& Politis, P. K. Nuclear receptors in neural stem/progenitor cell homeostasis. Cell. Mol. Life Sci. 74, 4097-4120 (2017).

35. Gaspar-Maia, A., Alajem, A., Meshorer, E. \& Ramalho-Santos, M. Open chromatin in pluripotency and reprogramming. Nat. Rev. Mol. Cell Biol. 12, 36-47 (2011).

36. Selth, L. A., Sigurdsson, S. \& Svejstrup, J. Q. Transcript Elongation by RNA Polymerase II. Annu. Rev. Biochem. 79, 271-93 (2010).

37. Yeo, G. \& Burge, C. B. Maximum Entropy Modeling of Short Sequence Motifs with Applications to RNA Splicing Signals. J. Comput. Biol. 11, 377394 (2004).

38. Corvelo, A., Hallegger, M., Smith, C. W. J. \& Eyras, E. Genome-Wide Association between Branch Point Properties and Alternative Splicing. PLoS Comput. Biol. 6, e1001016 (2010).

39. Ray, D. et al. A compendium of RNA-binding motifs for decoding gene regulation. Nature 499, 172-177 (2013).

40. Ule, J. et al. An RNA map predicting Nova-dependent splicing regulation. Nature 444, 580-586 (2006).

41. Zhang, C. et al. Defining the regulatory network of the tissue-specific splicing factors Fox-1 and Fox-2. Genes Dev. 22, 2550-63 (2008).

42. Thomas, L. et al. Identification of synaptophysin as a hexameric channel protein of the synaptic vesicle membrane. Science (80-. ). 242, 1050-1053 (1988).

43. Schreiner, D. et al. Targeted combinatorial alternative splicing generates brain region-specific repertoires of neurexins. Neuron 84, 386-98 (2014).

44. Patton, J. G., Porro, E. B., Galceran, J., Tempst, P. \& Nadal-Ginard, B. Cloning and characterization of PSF, a novel pre-mRNA splicing factor. Genes Dev. 7, 393-406 (1993).

45. Takeuchi, A. et al. Loss of Sfpq Causes Long-Gene Transcriptopathy in the Brain. Cell Rep. 23, 1326-1341 (2018).

46. Bourgeron, T. From the genetic architecture to synaptic plasticity in autism spectrum disorder. Nat. Rev. Neurosci. 16, 551-563 (2015).

47. Koh, F. M. et al. Emergence of hematopoietic stem and progenitor cells involves a Chd1-dependent increase in total nascent transcription. Proc. Natl. Acad. Sci. U. S. A. 112, E1734-43 (2015). 
Maslon et al.

48. Percharde, M., Wong, P. \& Ramalho-Santos, M. Global Hypertranscription in the Mouse Embryonic Germline. Cell Rep. 19, 1987-1996 (2017).

49. Artus, J., Babinet, C. \& Cohen-Tannoudji, M. The cell cycle of early mammalian embryos: Lessons from genetic mouse models. Cell Cycle (2006). doi:10.4161/cc.5.5.2500

50. Takahashi, T., Nowakowski, R. S. \& Caviness, V. S. The cell cycle of the pseudostratified ventricular epithelium of the embryonic murine cerebral wall. J. Neurosci. 15, 6046-57 (1995).

51. Ahmed, K. et al. Global Chromatin Architecture Reflects Pluripotency and Lineage Commitment in the Early Mouse Embryo. PLoS One 5, e10531 (2010).

52. Azuara, V. et al. Chromatin signatures of pluripotent cell lines. Nat. Cell Biol. 8, 532-538 (2006).

53. Wen, B., Wu, H., Shinkai, Y., Irizarry, R. A. \& Feinberg, A. P. Large histone H3 lysine 9 dimethylated chromatin blocks distinguish differentiated from embryonic stem cells. Nat. Genet. 41, 246-50 (2009).

54. Lienert, F. et al. Genomic Prevalence of Heterochromatic H3K9me2 and Transcription Do Not Discriminate Pluripotent from Terminally Differentiated Cells. PLoS Genet. 7, e1002090 (2011).

55. Fiszbein, A. et al. Alternative Splicing of G9a Regulates Neuronal Differentiation. Cell Rep. 14, 2797-808 (2016).

56. Gavin, D. P., Grayson, D. R., Varghese, S. P. \& Guizzetti, M. Chromatin Switches during Neural Cell Differentiation and Their Dysregulation by Prenatal Alcohol Exposure. Genes (Basel). 8, 137 (2017).

57. Meshorer, E. et al. Hyperdynamic Plasticity of Chromatin Proteins in Pluripotent Embryonic Stem Cells. Dev. Cell 10, 105-116 (2006).

58. Veloso, A. et al. Rate of elongation by RNA polymerase II is associated with specific gene features and epigenetic modifications. Genome Res. 24, 896-905 (2014).

59. Jonkers, I. \& Lis, J. T. Getting up to speed with transcription elongation by RNA polymerase II. Nat. Rev. Mol. Cell Biol. 16, 167-177 (2015).

60. Schor, I. E., Rascovan, N., Pelisch, F., Alló, M. \& Kornblihtt, A. R. Neuronal cell depolarization induces intragenic chromatin modifications affecting NCAM alternative splicing. Proc. Natl. Acad. Sci. U. S. A. 106, 4325-30 (2009).

61. Alló, M. et al. Control of alternative splicing through siRNA-mediated transcriptional gene silencing. Nat. Struct. Mol. Biol. 16, 717-724 (2009).

62. Gabel, H. W. et al. Disruption of DNA-methylation-dependent long gene repression in Rett syndrome. Nature 522, 89 (2015).

63. King, I. F. et al. Topoisomerases facilitate transcription of long genes linked to autism. Nature 501, 58-62 (2013). 
Maslon et al.

64. Lagier-Tourenne, C. et al. Divergent roles of ALS-linked proteins FUS/TLS and TDP-43 intersect in processing long pre-mRNAs. Nat. Neurosci. 15, 148897 (2012).

65. De Rubeis, S. et al. Synaptic, transcriptional and chromatin genes disrupted in autism. Nature 515, 209-215 (2014).

66. Adams, D. J. et al. A genome-wide, end-sequenced 129Sv BAC library resource for targeting vector construction. Genomics 86, 753-758 (2005).

67. Warming, S., Costantino, N., Court, D. L., Jenkins, N. A. \& Copeland, N. G. Simple and highly efficient BAC recombineering using galK selection. Nucleic Acids Res. 33, e36-e36 (2005).

68. Liu, P., Jenkins, N. A. \& Copeland, N. G. A highly efficient recombineeringbased method for generating conditional knockout mutations. Genome Res. 13, 476-84 (2003).

69. Joyner, A. L. Gene targeting : a practical approach. (Oxford University Press, 2000).

70. Nagy, A., Gertsenstein, M., Vintersten, K. \& Behringer, R. Counting chromosomes in embryonic stem (ES) cells. Cold Spring Harb. Protoc. 2009, pdb.prot4404 (2009).

71. Cong, L. et al. Multiplex genome engineering using CRISPR/Cas systems. Science 339, 819-23 (2013).

72. Crichton, J. H. et al. Tex19.1 promotes Spo11-dependent meiotic recombination in mouse spermatocytes. PLOS Genet. 13, e1006904 (2017).

73. Yen, S.-T. et al. Somatic mosaicism and allele complexity induced by CRISPR/Cas9 RNA injections in mouse zygotes. Dev. Biol. 393, 3-9 (2014).

74. Folco, E. G., Lei, H., Hsu, J. L. \& Reed, R. Small-scale nuclear extracts for functional assays of gene-expression machineries. J. Vis. Exp. (2012). doi: $10.3791 / 4140$

75. Langmead, B., Trapnell, C., Pop, M. \& Salzberg, S. L. Ultrafast and memoryefficient alignment of short DNA sequences to the human genome. Genome Biol. 10, R25 (2009).

76. Fuchs, G. et al. Simultaneous measurement of genome-wide transcription elongation speeds and rates of RNA polymerase II transition into active elongation with 4sUDRB-seq. Nat. Protoc. 10, 605-618 (2015).

77. Tapial, J. et al. An atlas of alternative splicing profiles and functional associations reveals new regulatory programs and genes that simultaneously express multiple major isoforms. Genome Res. 27, 1759-1768 (2017).

78. Merico, D., Isserlin, R., Stueker, O., Emili, A. \& Bader, G. D. Enrichment map: a network-based method for gene-set enrichment visualization and interpretation. PLoS One 5, e13984 (2010).

79. Shannon, P. et al. Cytoscape: a software environment for integrated models of biomolecular interaction networks. Genome Res. 13, 2498-504 (2003). 
Figure 1 bioRxiv preprint doi: https://doi.org/10.1101/426577; this version posted November 4, 2018. The copyright holder for this preprint (which
was not certified by peer review) is the author/funder, who has granted bioRxiv a license to display the preprint in perpetuity. It is made

Figure 1 bioRxiv preprint doi: https://doi.org/10.1101/426577; this version posted November 4,2018 . The copyright holder for this preprint (which
was not certified by peer review) is the author/funder, who has granted bioRxiv a license to display the preprint in perpetuity. It is made a was not certified by peer review) is the author/funder, who has granted bioRxiv a license to display the preprint in perpetuity. It is made
available under aCC-BY-NC-ND 4.0 International license.

Polr2a locus

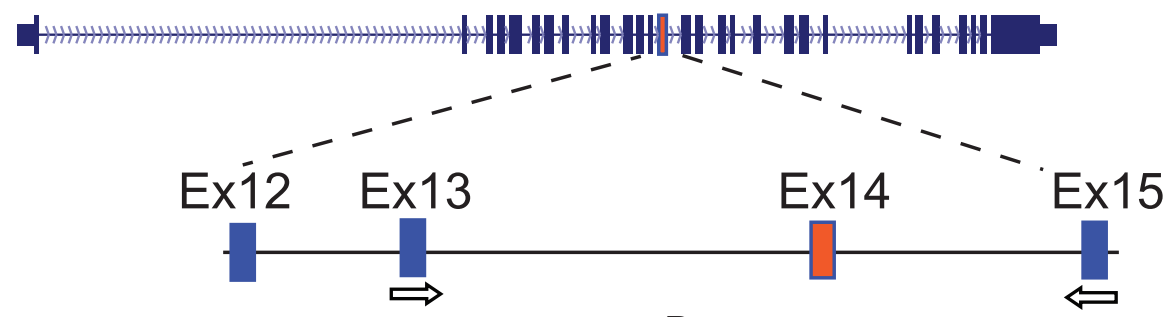

Targeting vector

E B

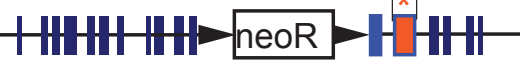

CGA $\rightarrow$ CAT

$\downarrow$ Homologous recombination

Targeted locus

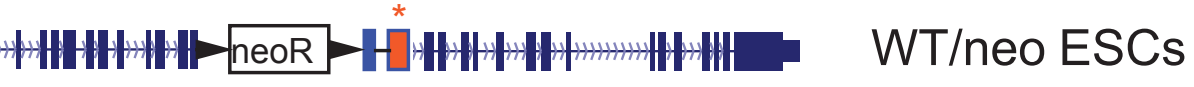

Cre recombination

Slow Polr2a locus

Cre recombination

a

2nd round of targeting

slow/slow ESCs

b

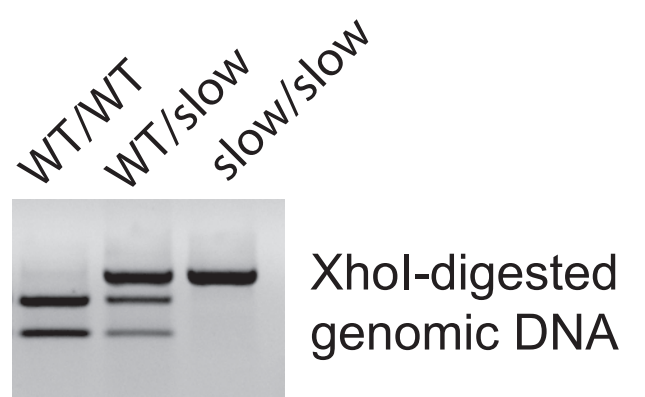

C

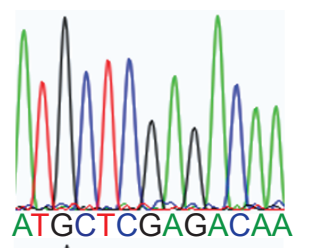

WT/WT

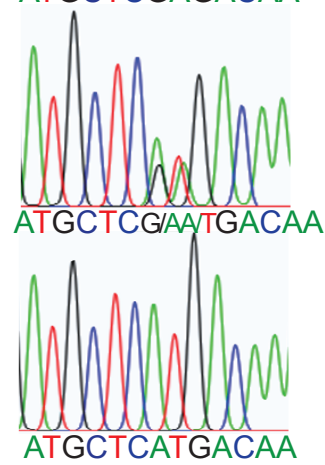

WT/slow

slow/slow

WTNT d

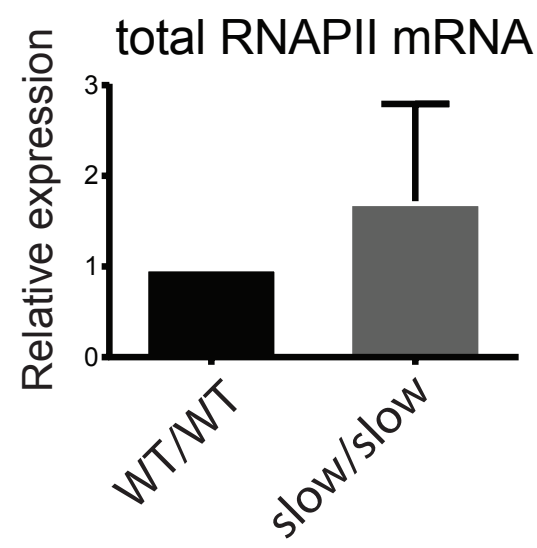

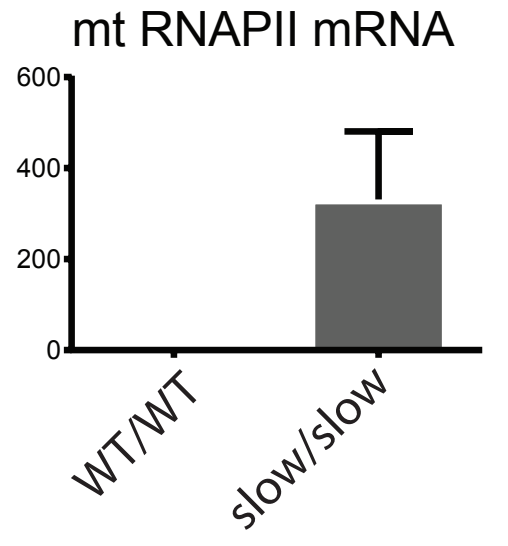

Forward primer

WT/slow allele A CTC CAG GAAACA CAT TGC slow allele only CGA ATT CTC AAT GAT GCT CAT

(1)

\begin{abstract}
A WT/neo ESCs
\end{abstract}


Finure DoRxiv preprint doi: https://doi.org/10.1101/426577; this version posted November 4, 2018. The copyright holder for this preprint (which Figure was not certified by peer review) is the author/funder, who has granted bioRxiv a license to display the preprint in perpetuity. It is made a available under aCC-BY-NC-ND 4.0 International license.

\section{Polr2a locus}

d

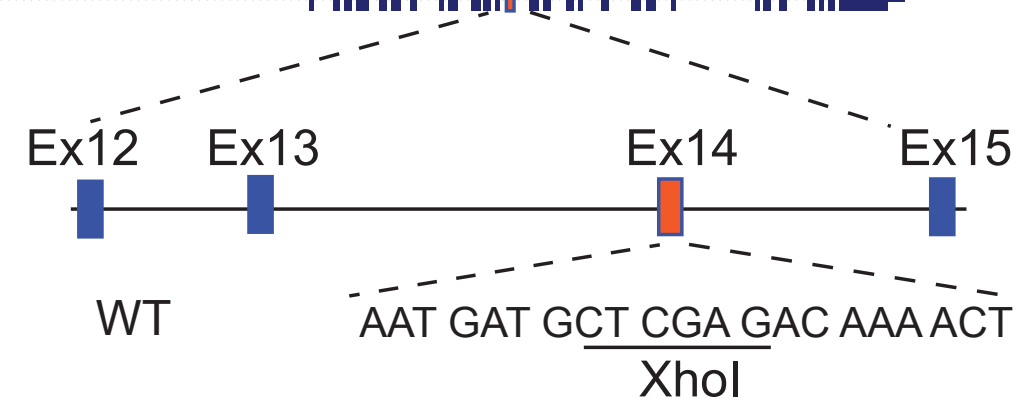

silent oligo

slow oligo

$$
\begin{gathered}
\text { - - -AAT GAT GCT AGG GAC AAA ACT - - - } \\
\text { - - -AAT GAT GCT CAT GAC AAA ACT - - - } \\
\text { R749H } \\
\text { xhol }
\end{gathered}
$$

b

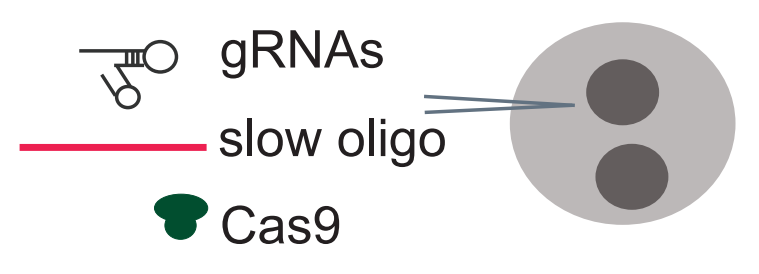

C

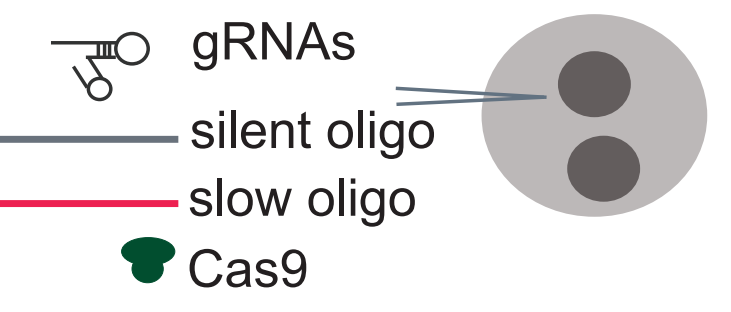

\begin{tabular}{|c|l|c|c|}
\cline { 2 - 4 } \multicolumn{1}{c|}{} & Genotype & E3.5 & Born \\
\hline WT mice & WT/WT & 34 & 47 \\
\hline Slow hets & WT/slow & 12 & 0 \\
\hline Slow homozyg & slow/slow & 1 & 0 \\
\hline
\end{tabular}

\begin{tabular}{|c|l|c|c|c|}
\cline { 2 - 5 } \multicolumn{1}{c|}{} & Genotype & E3.5 & E9.5 & Born \\
\hline \multirow{3}{*}{ WT mice } & WT/WT & 86 & 64 & 45 \\
\cline { 2 - 5 } & WT/silent & 7 & 9 & 4 \\
\cline { 2 - 5 } & silent/silent & 4 & 10 & 2 \\
\hline \multirow{2}{*}{ Slow hets } & WT/slow & 20 & 1 & 0 \\
\cline { 2 - 5 } & silent/slow & 0 & 0 & 0 \\
\hline Slow homozyg & slow/slow & 0 & 0 & 0 \\
\hline
\end{tabular}


Fiqure 3ioRxiv preprint doi: https://doi.org/10.1101/426577; this version posted November 4, 2018. The copyright holder for this preprint (which

FIgure 3 was not certified by peer review) is the author/funder, who has granted bioRxiv a license to display the preprint in perpetuity. It is made

DRB treatment DRB wash

b
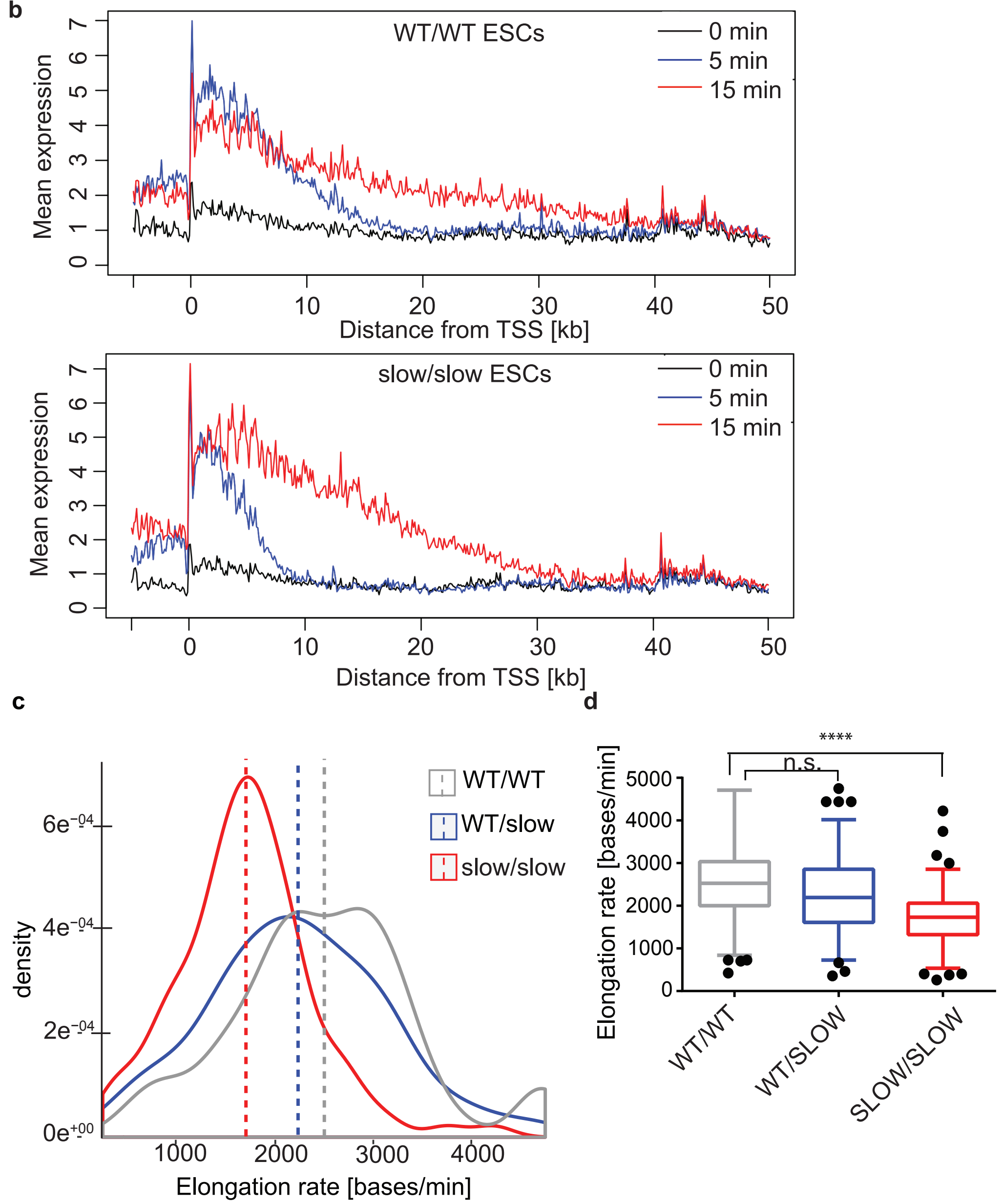

Elongation rate [bases/min]

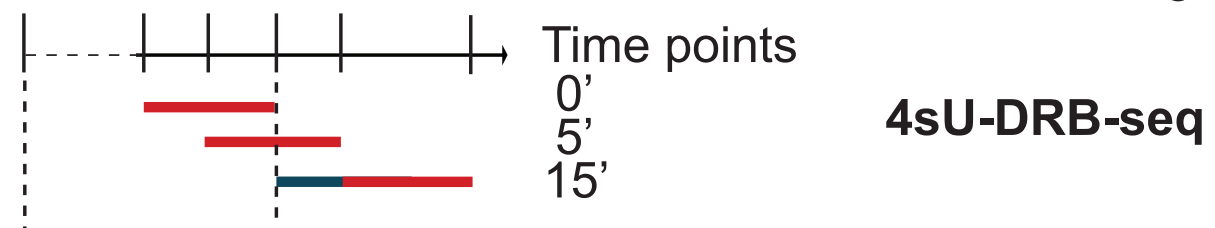


Fiqure 4 ioRxiv preprint doi: https://doi.org/10.1101/426577; this version posted November 4, 2018. The copyright holder for this preprint (which

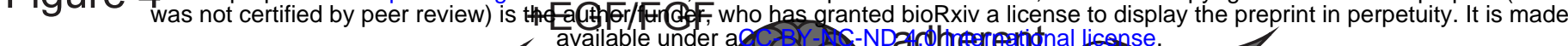

a

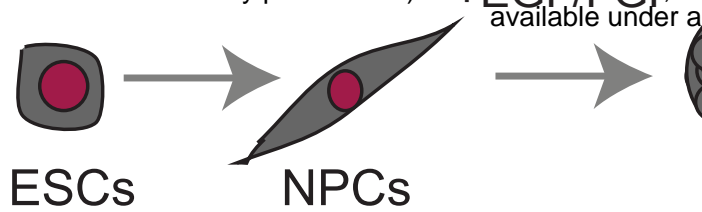

day 0 day 7

poly-ornithine/laminin + CAMP/AA

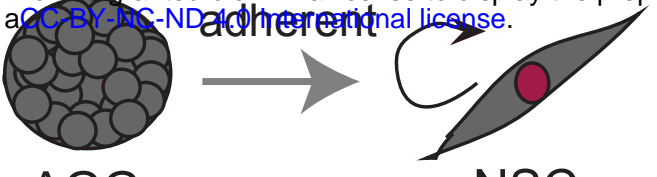

AGG

day 10

NSCs

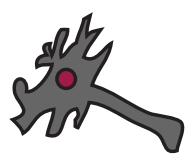

Neurons

day 21 b

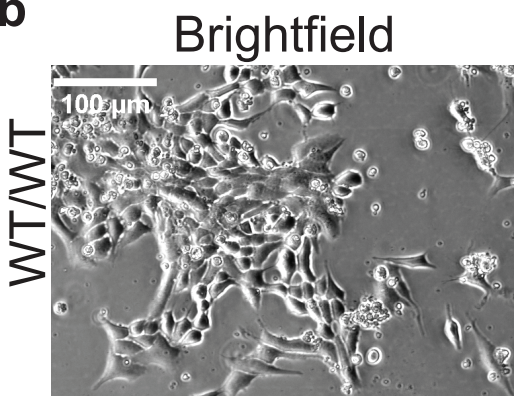

$\frac{3}{\frac{3}{3}}$

c

C

$\frac{3}{0}$

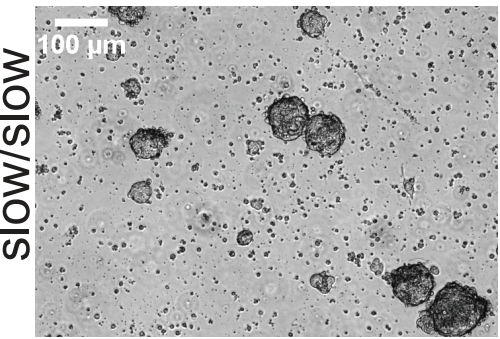

DAPITuj1

E

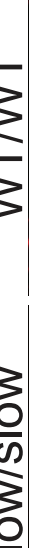

50 um
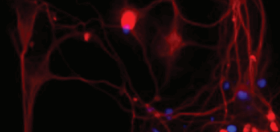

DAPISox1

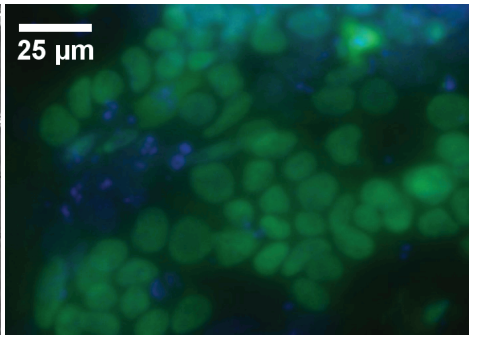

$25 \mu \mathrm{m}$

d
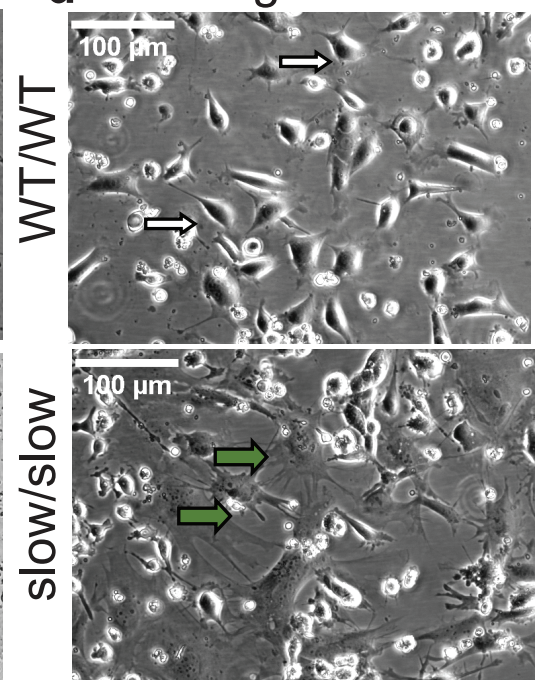

DAPI Nestin
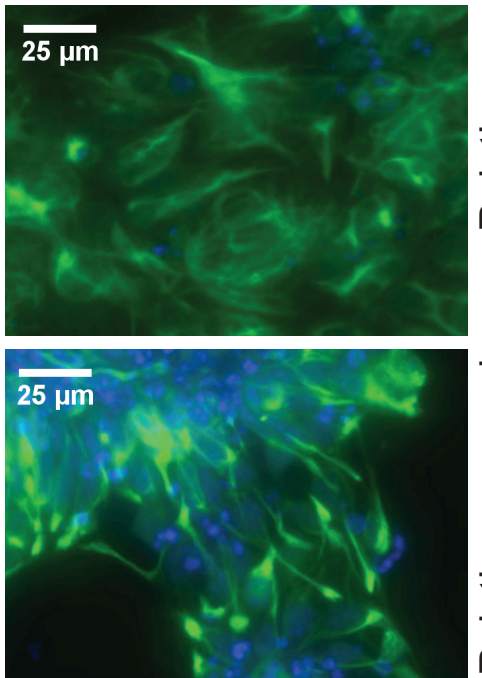

DAPINestinTuj1
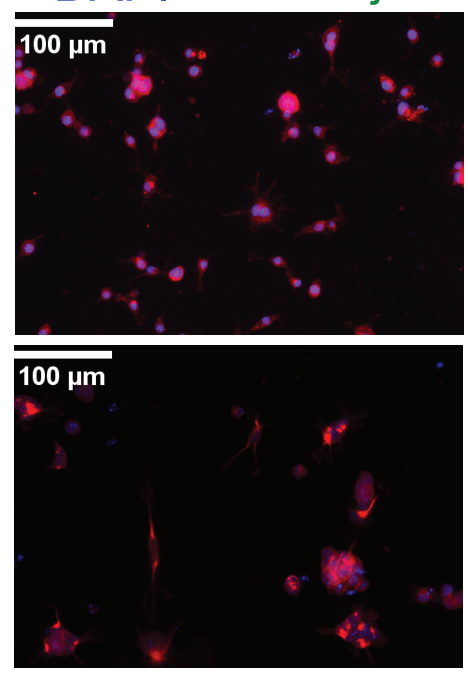

Nestin

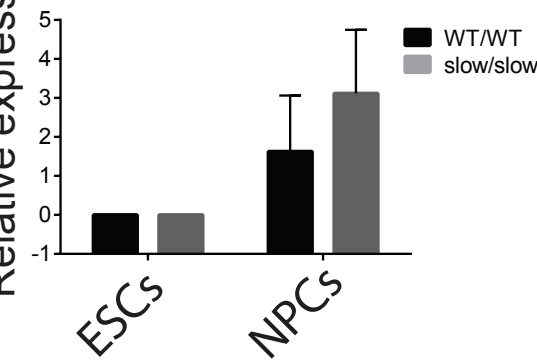

Pax6

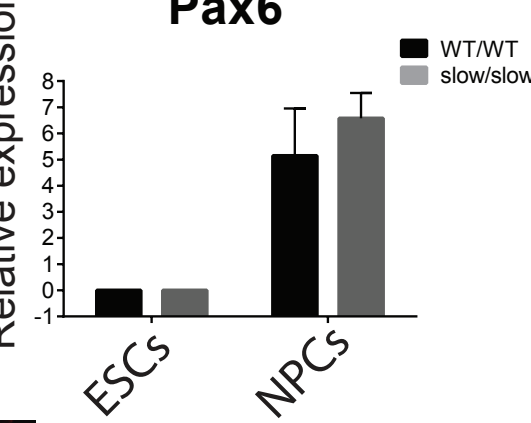




bioRxiv preprint doi: https://doi.org/10.1101/426577; this version posted November 4, 2018. The copyright holder for this preprint (which was not certified by peer review) is the author/funder, who has granted bioRxiv a license to display the preprint in perpetuity. It is made available under aCC-BY-NC-ND 4.0 International license. 
Einurn QioRxiv preprint doi: https://doi.org/10.1101/426577; this version posted November 4, 2018. The copyright holder for this preprint (which

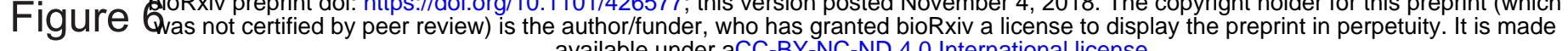

a Downregulated in slow/slow neurons

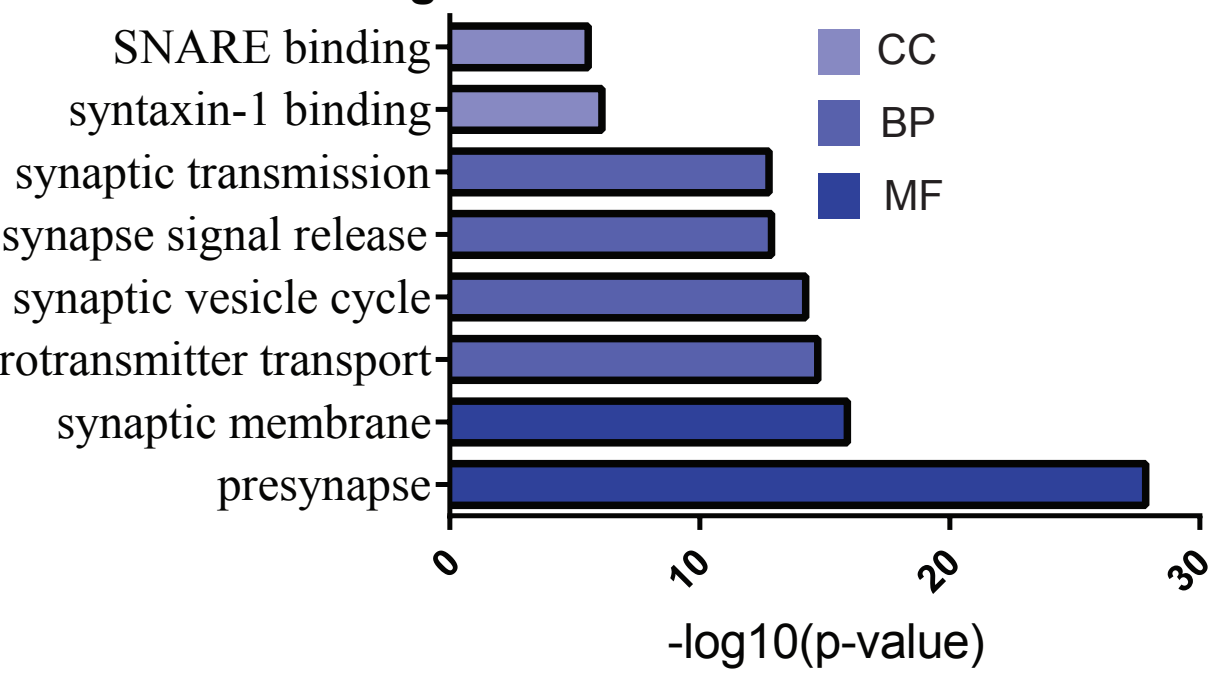

b neurotransmitter transport

synaptic membrane-
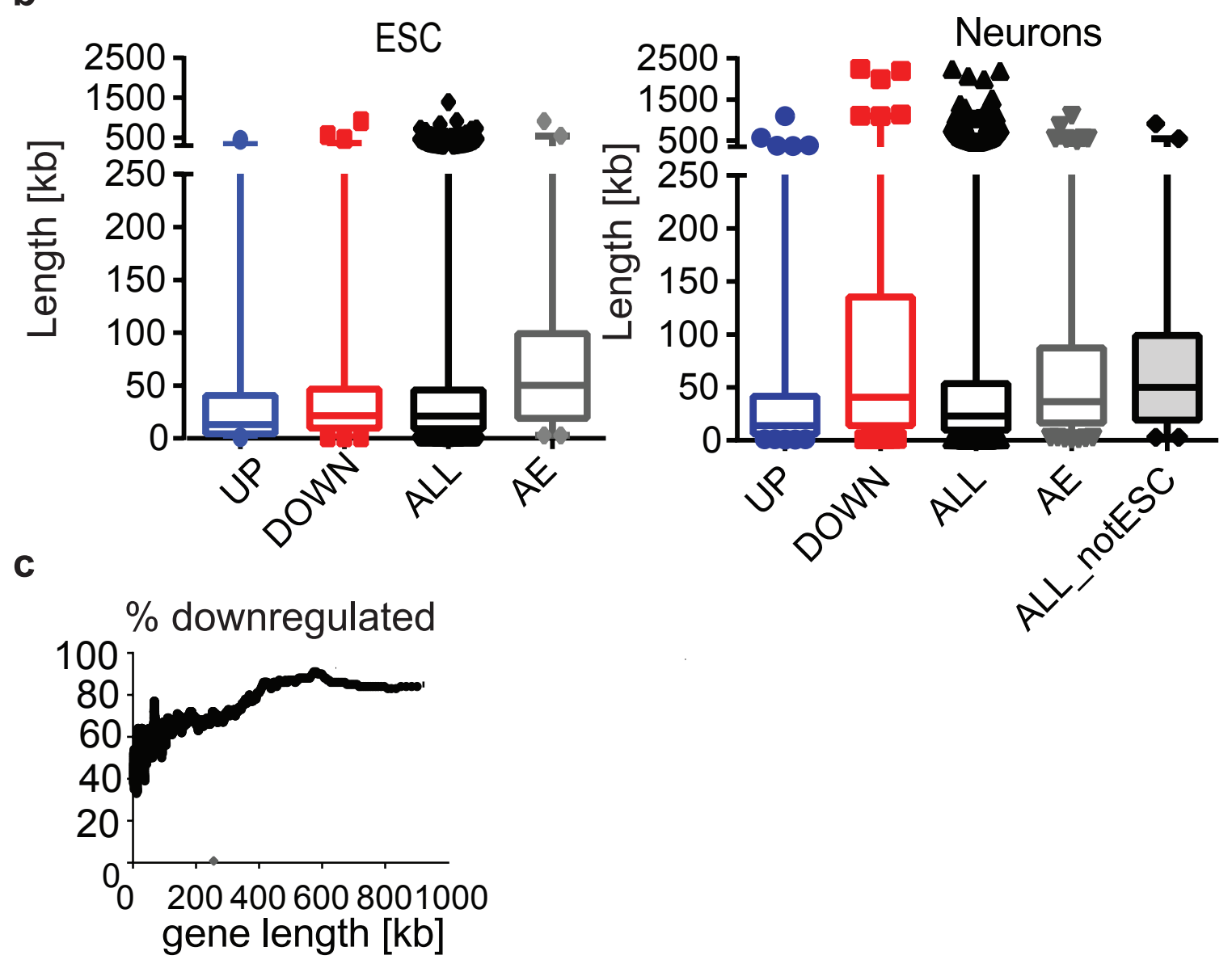


\begin{tabular}{|l|l|l|l|l|l|}
\hline Gene & Exon & AS & Protein change & Protein/Isoform function & Disease \\
\hline Kif1b & Ex27 & Skipped & $\begin{array}{l}\text { no PH domain-like, aa } \\
\text { change in GTPase domain }\end{array}$ & $\begin{array}{l}\text { long isoform transports } \\
\text { synaptic vesicle precursors }\end{array}$ & $\begin{array}{l}\text { Charcot-Marie-Tooth } \\
\text { Disease Type 2A }\end{array}$ \\
\hline Scrib & Ex36 & Skipped & $\begin{array}{l}\text { Shorter protein lacking } \\
\text { Discs domain }\end{array}$ & $\begin{array}{l}\text { scaffolding protein, key } \\
\text { role for neurotransmitter } \\
\text { release }\end{array}$ & $\begin{array}{l}\text { ASD, ADHD, } \\
\text { microcephaly }\end{array}$ \\
\hline Apbb1 & $\begin{array}{l}\text { MIC } \\
\text { Ex9 }\end{array}$ & Skipped & $\begin{array}{l}\text { Inclusion enhances } \\
\text { interaction with Kat5, but } \\
\text { not APP }\end{array}$ & $\begin{array}{l}\text { neuronal positioning and } \\
\text { axon outgrowth, synaptic } \\
\text { vesicle loading }\end{array}$ & ASD,Alzheimer's disease \\
\hline Dnm1 & Ex10 & Included & $\begin{array}{l}\text { aa substitution in } \\
\text { dynamin domain }\end{array}$ & $\begin{array}{l}\text { activity-dependent } \\
\text { synaptic vesicle } \\
\text { endocytosis and membrane } \\
\text { recycling }\end{array}$ & $\begin{array}{l}\text { epileptic encephalopathy, } \\
\text { Sennox-Gastaut }\end{array}$ \\
\hline Slg3 & Ex7 & Included & $\begin{array}{l}\text { shorter protein lacking } \\
\text { Discs large domain }\end{array}$ & $\begin{array}{l}\text { regulates cortical synapse } \\
\text { development }\end{array}$ & $\begin{array}{l}\text { ASD,non-syndromic } \\
\text { mental retardation }\end{array}$ \\
\hline Syn1 & Intron retention & & $\begin{array}{l}\text { synaptic vesicle release, } \\
\text { establishes synaptic vesicle } \\
\text { reserve pool }\end{array}$ & ASD, epilepsy \\
\hline Gabbr1 & Intron retention & $\begin{array}{l}\text { ORF disruption upon } \\
\text { sequence inclusion }\end{array}$ & $\begin{array}{l}\text { GABA receptor } \\
\text { ASD, Schizophrenia }\end{array}$ \\
\hline
\end{tabular}

Table 1. Examples of AS events presented in Supplementary Figure 7b 